Palleti, H.N.K.T., Zhang, S., Dulieu-Barton, J.M., Fruehmann, R.K. and Thomsen, O.T., "Influence of thermomechanical interaction effects on the failure behaviour of polymer foam cored sandwich panels”, Journal of Sandwich Structures and Materials, 17, 2015, 308-331. DOI: 10.1177/1099636214567602.

\title{
Influence of thermomechanical interaction effects on the failure behaviour of polymer foam cored sandwich panels
}

\author{
H N K T Palleti ${ }^{1}$, S Zhang ${ }^{2}$, R K Fruehmann ${ }^{3}$, J M Dulieu-Barton ${ }^{1,3 *}$, O T Thomsen ${ }^{1,3}$, \\ ${ }^{1}$ Department of Mechanical and Manufacturing Engineering, Aalborg University, Aalborg DK-9220, \\ Denmark
}

${ }^{2}$ Science and Technology on Integrated Logistics Support Laboratory, National University of Defense Technology, China

\footnotetext{
${ }^{3}$ Faculty of Engineering and the Environment, University of Southampton, Southampton, SO17 1BJ, UK
}

* Corresponding author e-mail: janice@soton.ac.uk

\begin{abstract}
The paper presents an experimentally based and numerically supported investigation of the collapse behaviour of polymer foam cored sandwich beams subjected to combined mechanical and thermal loading. Recent analytical and numerical modelling results available in the literature have ascertained that collapse may be due to loss of stability induced by nonlinear interactions between mechanical loads and thermally induced deformations, when accounting for the reduction of the polymer foam core mechanical properties with increasing temperature. In the paper, experiments are devised whereby a thermal gradient is introduced into a sandwich beam specimen loaded in three point bending. The experiments cover a range of temperatures where one face sheet is heated from room temperature $\left(25^{\circ} \mathrm{C}\right)$ to just below the glass transition temperature of the polymer foam core $\left(70^{\circ} \mathrm{C}\right)$ and the other face sheet remains at room temperature. Digital image correlation (DIC) is used to obtain the local displacement field of the sandwich beam and its temperature is monitored using an infrared detector and thermocouples. The experimental results are compared with the predictions of both a generally nonlinear finite element model and an analytical so-called high-order sandwich panel theory (HSAPT) model. It is important to note that the HSAPT model has clear limitations as it takes into account only the geometric nonlinearity and thermal degradation of the foam core elastic properties, and it further assumes that the sandwich constituents are linear elastic with infinite straining capability. The HSAPT model predicts the occurrence of a strongly nonlinear load response leading to loss of stability (limit point
\end{abstract}


Palleti, H.N.K.T., Zhang, S., Dulieu-Barton, J.M., Fruehmann, R.K. and Thomsen, O.T., "Influence of thermomechanical interaction effects on the failure behaviour of polymer foam cored sandwich panels”, Journal of Sandwich Structures and Materials, 17, 2015, 308-331. DOI: 10.1177/1099636214567602.

behaviour). However, the experiments show that for the investigated sandwich beam configuration it is necessary to include the nonlinear material properties in the modelling, as the nonlinear beam response leading to failure and collapse is significantly influenced by plastic deformations in the constituent materials. Thus, core indentation and extensive plasticity precedes the transition to loss of stability driven by geometric nonlinearity and thermomechanical interaction effects. Finite element analyses that include both geometric and material nonlinearities provide results that correlate closely with the experimental observations. The work presented lays the foundations of a methodology for validating complex thermomechanical behaviour in sandwich structures using non-contact full-field measurement systems, and it demonstrates that analytical or numerical models based on the assumption of linear elastic material behaviour (such as the HSAPT model referenced in the paper) generally cannot adequately describe the thermomechanical behaviour of foam cored sandwich structures.

\section{Introduction}

Sandwich structures are typically exposed to mechanical loading as well as to aggressive environmental conditions that may include elevated temperatures. Traditionally, a typical design process of such structures examines the responses due to the mechanical loads and the thermal loading, i.e. the deformations induced by thermal sources, separately. However, the interaction between the mechanical and thermal loads may lead to an unsafe response with loss of stability and structural integrity, particularly when the deformations are large and the mechanical properties (e.g. stiffness and strength) reduce as the temperature is raised. Significant degradation of the mechanical properties of polymer foam core materials may occur well within the operation temperature range. It should be noted that in the present context the term "degradation" is used as a short form of "degradation or reduction of mechanical properties”. In general, this thermal degradation of polymer foam cored sandwich structures is not thoroughly understood by researchers and industry.

There is a growing concern within the wind turbine blade, marine and aeronautical sectors about the simultaneous action of mechanical loads and elevated temperatures on polymer foam cored sandwich structures, which may compromise the structural integrity. The manufacturers of polymer foam materials, including PVC, PET, PMI and other types, offer limited and incomplete information about the temperature dependency of the core mechanical 
Palleti, H.N.K.T., Zhang, S., Dulieu-Barton, J.M., Fruehmann, R.K. and Thomsen, O.T., "Influence of thermomechanical interaction effects on the failure behaviour of polymer foam cored sandwich panels”, Journal of Sandwich Structures and Materials, 17, 2015, 308-331. DOI: 10.1177/1099636214567602.

properties. Furthermore they do not provide any significant design guidelines about the combined influence of mechanical and thermal loads.

Recently, due to the growing concern regarding the behaviour of polymer foam cored sandwich structures when exposed to combined thermal and mechanical loading scenarios, several researchers have considered the thermomechanical response of sandwich structures. A significant amount of the research has involved the use of high-order theories to model the thermomechanical response of laminated or sandwich panels including Najafizadeh and Heydari [1], Dafedar and Desai [2], Kapuria and Achary [3], Shiau and Kuo [4], Matsunaga [5], Dawe [6] and Cooke [7]. However, none of these have included the core throughthickness flexibility.

A more comprehensive approach is offered by the so-called high-order sandwich panel theory (HSAPT), which models the layered sandwich panel as two face sheets and a core material that are interconnected through the equilibrium and compatibility conditions. Moreover, the HSAPT formulation incorporates the through-thickness flexibility of the core, but assumes that the core in-plane stiffness is negligible. The HSAPT approach has been used in several studies that investigate the influence of hygrothermal effects, buckling (global and local) and nonlinear response, see Frostig [8]; Frostig and Baruch [9]; Sokolinsky and Frostig [10], Frostig and Thomsen [11, 12] and Frostig et al [13]. Most importantly in the context of the present paper, Frostig and Thomsen studied thermal buckling and post-buckling of foam cored sandwich structures by adopting the HSAPT approach with the assumption that the core properties are either temperature independent [12] or temperature dependent [14]. The HSAPT formulation was extended to include geometrical nonlinearity and the simultaneous influence of mechanical and thermal loads [15]. Recently, Santiuste et.al [16] investigated the thermomechanical nonlinear response of circular sandwich plates with a compliant core that possesses temperature dependent properties, and also presented a detailed discussion of the computational difficulties associated with solving the elastic geometrically nonlinear finite element (FE) model [16] subjected to thermomechanical loads. In [8-16] it is assumed that the constituents behave as linear elastic materials, and thereby that they possess unlimited straining capability; albeit not mentioned explicitly in the publications of Frostig and his coworkers. Under these restrictive assumptions the HSAPT model predictions demonstrate that a mechanical load response which is linear and stable at room temperature, may change to a highly nonlinear load response with loss of stability (limit point behaviour) at elevated 
Palleti, H.N.K.T., Zhang, S., Dulieu-Barton, J.M., Fruehmann, R.K. and Thomsen, O.T., "Influence of thermomechanical interaction effects on the failure behaviour of polymer foam cored sandwich panels”, Journal of Sandwich Structures and Materials, 17, 2015, 308-331. DOI: 10.1177/1099636214567602.

temperatures due to the thermal degradation of the elastic properties of the sandwich constituents, in particular the polymer foam core $[15,16]$.

The objective of the work described in the present paper is to devise an experimental methodology to study the thermomechanical behaviour of polymer foam cored sandwich beams subjected to simultaneous mechanical and thermal loads. The experimental design is supported by extensive FE analyses. In particular, the study aims to assess if the nonlinear thermomechanical interaction effects leading to loss of stability can be triggered experimentally under loading and boundary conditions replicating the conditions used in $[12$, 15]. Thus, the experimental investigation is conducted on polymer foam cored sandwich beams subjected to a point load at mid-span and subjected to a thermal field that is either homogeneous or varies linearly through the sandwich beam thickness. For simplicity, only the case of simple support conditions imposed at the ends of the lower face sheet is considered, even though other combinations of boundary conditions are included in the studies presented in $[12,15]$. Figure 1(a) shows the dimensions and geometry of the foam cored sandwich beam configuration used throughout the work described in the paper. Figure 1(b) shows the experimental set up in a standard servo-hydraulic test machine; a detailed description of the experimental set up is given later in the paper.

The experiments are conducted over a range of temperatures from room temperature $\left(25^{\circ} \mathrm{C}\right)$ to below the glass transition temperature of the polymer foam core $\left(70^{\circ} \mathrm{C}\right)$. Digital image correlation (DIC) is used to obtain the local displacement field in the sandwich beam, and the temperature is monitored using an infrared detector and thermocouples. The results are compared with the predictions of both nonlinear FE analyses and the HSAPT approach proposed in [12, 15], which includes geometric nonlinearity and thermal degradation/reduction of the foam core elastic properties. Finally, nonlinear FE analyses that account for orthotropic material nonlinearity (i.e. plasticity) as well as geometric nonlinearity are conducted to further understand the failure of foam cored sandwich beams at room temperature $\left(25^{\circ} \mathrm{C}\right)$ subjected to three-point bending.

\section{Test specimens and definition of material properties}

The sandwich beams were made using a $25 \mathrm{~mm}$ thick PVC foam core (Divinycell H100 manufactured by DIAB, Sweden) and a $0.9 \mathrm{~mm}$ thick aluminium alloy face sheet (AA6082T6). The face sheets were bonded to the core using Prime $20 \mathrm{LV}$, a low viscosity epoxy resin manufactured by Gurit. The adhesive was cured under uniform pressure inside a vacuum bag 
Palleti, H.N.K.T., Zhang, S., Dulieu-Barton, J.M., Fruehmann, R.K. and Thomsen, O.T., "Influence of thermomechanical interaction effects on the failure behaviour of polymer foam cored sandwich panels”, Journal of Sandwich Structures and Materials, 17, 2015, 308-331. DOI: 10.1177/1099636214567602.

to produce a minimal thickness and uniform bond layer with low void content. Sandwich beam specimens of $455 \times 50 \times 26.8 \mathrm{~mm}$ (length $\times$ width $\times$ thickness) were cut from a larger panel and subjected to three-point bending with simply supported ends, as shown in Figure 1 (the sandwich beam span is $450 \mathrm{~mm}$ ). The dimensions of the sandwich beam were selected to fit the constraints of the test machine, the requirement to ensure a uniform temperature across the length and width and to meet practical considerations with regard to spatial resolution of the thermal and displacement measurements. The aluminium alloy was chosen for the face sheet as its very high thermal conductivity promotes a uniform temperature distribution throughout the face sheet and hence across the top surface of the foam core. Also, the aluminium alloy has a minimal loss of stiffness over the temperature range from 25 to $100^{\circ} \mathrm{C}$ [17].

Six 'dog bone' samples, with a gauge area of $50 \times 12.5 \mathrm{~mm}$, were cut from the aluminium sheet used for the face sheets to obtain the room temperature stress-strain behaviour. DIC [18] was used to obtain the strains parallel and transverse to the loading direction. The test specimens were constructed so that the material behaviour to failure could be obtained both parallel and transverse to the sheet rolling direction. A typical stress-strain curve for the aluminium alloy specimens loaded in the rolling direction is shown in Figure 2(a). The scatter in the six tests was less than $0.5 \%$ for both the Young's modulus and the $0.2 \%$ offset proof stress.

Divinycell H100 foam core material is of medium density and was chosen as it is representative of a large range of PVC foam cores. Detailed characterisation of the elastic properties of the H100 foam has been conducted over a range of temperatures from 20 to $90^{\circ} \mathrm{C}$ using ASTM standard test specimen geometries [19, 20]. H100 foam has been shown to be orthotropic, with a greater stiffness in the through-thickness direction. The full failure envelope in tension and shear has been obtained at $25^{\circ} \mathrm{C}$ using a modified Arcan rig as described in [21]. The stress-strain curves are presented in Figure 2(b), where the stress-strain curve in compression at $25^{\circ} \mathrm{C}$ was obtained for the work presented in this paper using a further development of the modified Arcan rig described in [21].

The nonlinear FE analyses were conducted using the software package ABAQUS/Standard ver. 6.10 [22]. To implement the material data in the nonlinear FE model, a number of assumptions and simplifications have been made. The face sheet elastic behaviour is defined in terms of the Young's modulus $\left(E_{f}\right)$ and Poisson's ratio $\left(v_{f}\right)$. These are assumed to be 
Palleti, H.N.K.T., Zhang, S., Dulieu-Barton, J.M., Fruehmann, R.K. and Thomsen, O.T., "Influence of thermomechanical interaction effects on the failure behaviour of polymer foam cored sandwich panels”, Journal of Sandwich Structures and Materials, 17, 2015, 308-331. DOI: 10.1177/1099636214567602.

independent of temperature. The elastic response of the core is modelled using the Young's moduli ( $E_{1 c}$ and $E_{2 c}$ ), the shear moduli $\left(G_{12 c}\right)$ and the major Poisson's ratio $\left(v_{12 c}\right)$. The material orientation 1 is in the through-thickness direction ( $z$ in Figure 1), and orientation 2 is the foam in-plane direction ( $x$ direction in Figure 1$)$. Room temperature $\left(25^{\circ} \mathrm{C}\right)$ properties of the aluminium alloy face sheet and the foam core are listed in Table 1 . The properties for the aluminium are given in the sheet rolling direction only, as the differences in the elastic properties parallel and transverse to the sheet rolling direction were found to be negligible. Note that the coefficient of thermal expansion (CTE) in Table 1 is given as an isotropic parameter. Manufacturers data giving separate values in the 1 and 2 directions is not available.

Table 1: Elastic properties of AA6082-T6 and Divinycell $\mathrm{H100}$ at room temperature

\begin{tabular}{|c|c|c|c|c|c|}
\hline Material & $E_{1}(\mathrm{MPa})$ & $E_{2}(\mathrm{MPa})$ & $G_{12}(\mathrm{MPa})$ & $v_{12}$ & $\mathrm{CTE}\left(\mathrm{K}^{-1}\right)$ \\
\hline AA6082-T6 & $71000( \pm 0.21 \%)$ & - & - & $0.30( \pm 5 \%)$ & $23 \times 10^{-6}[23]$ \\
\hline Divinycell H100 & $132[19]$ & $59[19]$ & $32[20]$ & $0.40[19]$ & $35 \times 10^{-6}[24]$ \\
\hline
\end{tabular}

CTE is the coefficient of linear thermal expansion.

In the nonlinear FE model, plasticity is defined in terms of a multilinear approximation of the full stress-strain curves for both the aluminium alloy face sheets and the polymer foam core material. Isotropic yielding behaviour is assumed for the face sheets, and the von Mises yielding theory [25] is adopted for conducting the nonlinear FE analyses. Accordingly, the yield stress for the face sheets, below which the plastic strain is zero, is defined. After this the transition from the elastic to elasto-plastic material range is defined using a set of yield stress terms $\left(\bar{\sigma}_{f}\right)$ and plastic strain terms $\left(\varepsilon_{f}^{p l}\right)$ that depend on the chosen multi-linear elasto-plastic stress-strain relationship. Yielding of the polymer foam core is defined using Hill's anisotropic plasticity theory [25] where the plastic potential or yield criterion is a general extension of von Mises yield criterion as defined by the following expression:

$$
2 f\left(\sigma_{i j}\right) \equiv F\left(\sigma_{y}-\sigma_{z}\right)^{2}+G\left(\sigma_{y}-\sigma_{z}\right)^{2}+H\left(\sigma_{y}-\sigma_{z}\right)^{2}+2 L \tau_{y z}^{2}+2 M \tau_{z x}^{2}+2 N \tau_{x y}^{2}=1
$$

where $F, G, H, L, M$ and $N$ are material parameters that may be obtained from experiments and are defined as follows: 
Palleti, H.N.K.T., Zhang, S., Dulieu-Barton, J.M., Fruehmann, R.K. and Thomsen, O.T., "Influence of thermomechanical interaction effects on the failure behaviour of polymer foam cored sandwich panels”, Journal of Sandwich Structures and Materials, 17, 2015, 308-331. DOI: 10.1177/1099636214567602.

$$
\begin{gathered}
F=\frac{\sigma_{0}^{2}}{2}\left(\frac{1}{\bar{\sigma}_{22}^{2}}+\frac{1}{\bar{\sigma}_{33}^{2}}-\frac{1}{\bar{\sigma}_{11}^{2}}\right)=\frac{1}{2}\left(\frac{1}{R_{22}^{2}}+\frac{1}{R_{33}^{2}}-\frac{1}{R_{11}^{2}}\right) \\
G=\frac{\sigma_{0}^{2}}{2}\left(\frac{1}{\bar{\sigma}_{33}^{2}}+\frac{1}{\bar{\sigma}_{11}^{2}}-\frac{1}{\bar{\sigma}_{22}^{2}}\right)=\frac{1}{2}\left(\frac{1}{R_{33}^{2}}+\frac{1}{R_{11}^{2}}-\frac{1}{R_{22}^{2}}\right) \\
H=\frac{\sigma_{0}^{2}}{2}\left(\frac{1}{\bar{\sigma}_{11}^{2}}+\frac{1}{\bar{\sigma}_{22}^{2}}-\frac{1}{\bar{\sigma}_{33}^{2}}\right)=\frac{1}{2}\left(\frac{1}{R_{22}^{2}}+\frac{1}{R_{33}^{2}}-\frac{1}{R_{11}^{2}}\right) \\
L=\frac{3}{2}\left(\frac{\tau_{0}}{\bar{\tau}_{23}}\right)^{2}=\frac{3}{2 R_{23}^{2}} \\
M=\frac{3}{2}\left(\frac{\tau_{0}}{\bar{\tau}_{13}}\right)^{2}=\frac{3}{2 R_{13}^{2}} \\
N=\frac{3}{2}\left(\frac{\tau_{0}}{\bar{\tau}_{12}}\right)^{2}=\frac{3}{2 R_{12}^{2}}
\end{gathered}
$$

where $\bar{\sigma}_{i i}$ or $\bar{\tau}_{i j}$ are the measured yield stress values when the material is subjected to only $\sigma_{i i}$ or $\tau_{i j}$ stresses, respectively (i.e., in uniaxial normal or pure shear stress states), $\sigma_{0}$ is the chosen reference yield stress specified for the plasticity definition, $\tau_{0}=\sigma_{0} / \sqrt{3}$, and $R_{i j}$ are the stress ratios defined below:

$$
R_{i i}=\frac{\bar{\sigma}_{i i}}{\sigma_{0}} \text { and } \quad R_{i j}=\frac{\bar{\tau}_{i j}}{\tau_{0}}
$$

In simple terms, Eq. (8) defines the amount of orthotropic plasticity developed relative to the chosen reference plasticity ( $\sigma_{0}$ and $\tau_{0}$ ) defined in one material direction. The plastic strain $\varepsilon^{p l}$ is obtained using the associated plasticity flow rule [22, 25] i.e.

$$
d \varepsilon^{p l}=d \lambda \frac{\partial f}{\partial \sigma}=\frac{d \lambda}{f} b
$$

where $d \lambda$ is a proportionality factor and $b$ is derived from Eq. (1) to give the following [22]: 
Palleti, H.N.K.T., Zhang, S., Dulieu-Barton, J.M., Fruehmann, R.K. and Thomsen, O.T., "Influence of thermomechanical interaction effects on the failure behaviour of polymer foam cored sandwich panels”, Journal of Sandwich Structures and Materials, 17, 2015, 308-331. DOI: 10.1177/1099636214567602.

$$
b=\left[\begin{array}{c}
-G\left(\sigma_{z}-\sigma_{x}\right)+H\left(\sigma_{x}-\sigma_{y}\right) \\
F\left(\sigma_{y}-\sigma_{z}\right)-H\left(\sigma_{x}-\sigma_{y}\right) \\
-F\left(\sigma_{y}-\sigma_{z}\right)+G\left(\sigma_{z}-\sigma_{x}\right) \\
2 N \tau_{x y} \\
2 M \tau_{z x} \\
2 L \tau_{y z}
\end{array}\right]
$$

The above outlines how a general multi-axial plastic strain state in an orthotropic core material is evaluated using Hill's anisotropic plasticity theory. More details about the implementation of the plasticity model can be found in [22, 25]. For the practical implementation of the plasticity model in ABAQUS, a set of yield stresses and plastic strains in one material orientation ( $\bar{\sigma}_{c}$ and $\varepsilon_{c}^{p l}$, similar to isotropic yielding) are defined to represent the reference yield stresses $\sigma_{0}$. In addition, Hill's stress ratios $R_{11}, R_{22}, R_{12}, R_{13}$ and $R_{23}$ (considering the core is transversely isotropic according to $[20,21]$ ) that define plasticity of the core in the other material directions are defined see Eq. (8) and Ref. [25].

According to the above, the definition of material behaviour of the face sheets at a given temperature therefore requires two elastic material constants $\left(E_{f}, v_{f}\right)$ and $m$ parameters for the plasticity definition (set of $\bar{\sigma}_{f}$ and $\varepsilon_{f}^{p l}$ ), where $m$ is the number of separation points used in the multi-linear approximations of the stress strain curves. For example, for a bi-linear approximation of the face sheet $m=2$ and only two values of $\bar{\sigma}_{f}$ and $\varepsilon_{f}^{p l}$ are required. For the particular investigation presented in this paper a six segment approximation was used for the aluminium face sheets $(m=6)$ as shown in Figure 2(a), overlaid on the experimentally derived stress-strain curve. For defining the material behaviour of the transversely isotropic polymer foam core, 5 elastic constants $\left(E_{1 c}, E_{2 c}, v_{12 c}, G_{12 c}, G_{23 c}\right.$ ) are required, $n$ parameters are required for the plasticity definition (set of $\bar{\sigma}_{c}$ and $\left.\varepsilon_{c}^{p l}\right)$, and four stress ratios $\left(R_{11}, R_{22}\right.$, $\left.R_{12}, R_{23}\right)$. Thus, a total of $(2+m)$ material parameters for the face sheets, and $(9+n)$ material parameters for the core, are required at any given temperature to define the elasto-plastic material behaviour in the nonlinear FE model.

The core is more susceptible to yielding when subjected to compressive stresses than to tensile stresses. Thus, in all the cases considered core material yielding and subsequent failure (fracture) was triggered by either core compression (leading to crushing) or core shear, 
Palleti, H.N.K.T., Zhang, S., Dulieu-Barton, J.M., Fruehmann, R.K. and Thomsen, O.T., "Influence of thermomechanical interaction effects on the failure behaviour of polymer foam cored sandwich panels”, Journal of Sandwich Structures and Materials, 17, 2015, 308-331. DOI: 10.1177/1099636214567602.

rather than tensile core stresses. Accordingly, the Bauschinger-like effect [26] can be neglected for the present loading cases. Thus, it is assumed that Hill's anisotropic yielding theory can be used with the compression stress-strain curve shown in Figure 2(b) adopted for the definition of the elasto-plastic material behaviour of the polymer foam. Also it was assumed from the compressive stress-strain curve shown in Figure 2(b) that there are no plastic deformations in the core up to $1.5 \mathrm{MPa}\left(\bar{\sigma}_{c}\right)$.

\section{Experimental procedure}

The boundary conditions encompass two aspects, mechanical and thermal, as shown in Figure 1. The mechanical load was introduced using a servo-hydraulic test machine via a 12 mm diameter steel roller in the centre and simply supported at the ends. The sandwich beam ends overhung the support by $2.5 \mathrm{~mm}$. As the specimen was loaded images were captured with a 5 mega pixel LA Vision VC-imager E-lite digital camera (with a frame rate of $2 \mathrm{~Hz}$ ) with a $105 \mathrm{~mm}$ Sigma lens, and DIC was used to obtain the displacement during the loading. For the purpose of DIC, the side of the specimen was sprayed with black and white paint to form a random speckle. The DIC algorithm then tracks the movement of the speckles relative to a reference image, thereby providing a full-field map of the surface deformations from which both strains and point measurements of displacement were obtained. Images of the side surface of the beam specimen were recorded synchronously with the load data. DIC was performed using the commercially available software Davis 7.4 [27] by LaVision. The image captured at zero load was used as the reference image and the subset size was $64 \times 64$ pixel. The displacement accuracy was verified as about 0.02 pixel by performing image correlation between two images at zero load. A typical displacement field obtained using DIC is shown in Figure 3. It is seen that the largest displacement occurs at the mid-span, and the displacement decreases symmetrically towards the two ends of the specimen.

A through-thickness temperature gradient was achieved by heating the upper surface of the specimen using an infrared (IR) radiator (see Figure 1(b)), while maintaining the lower face sheet at ambient temperature by means of forced convection of the air below the specimen using an electric fan. This method of creating a temperature gradient was selected because it provides a non-contact solution that replicates heating through solar radiation. One challenge in achieving thermal boundary conditions that can be represented in a two dimensional FE or HSAPT models (that analyses sandwich beams or 2D panels), is the finite width of the specimen, which leads to a non-uniform temperature distribution across the specimen width 
Palleti, H.N.K.T., Zhang, S., Dulieu-Barton, J.M., Fruehmann, R.K. and Thomsen, O.T., "Influence of thermomechanical interaction effects on the failure behaviour of polymer foam cored sandwich panels”, Journal of Sandwich Structures and Materials, 17, 2015, 308-331. DOI: 10.1177/1099636214567602.

due to heat losses at the specimen sides. However, the two dimensional FE or HSAPT models necessarily assume a constant temperature across the width. To reduce the width-wise temperature gradient, insulation in the form of additional PVC foam was placed on both sides of the specimen during the heating process (see Figure 1(b)). Due to the space available in the test rig, the practical limit on the width of the insulation was approximately $25 \mathrm{~mm}$.

To assess the temperature distribution (especially across the specimen width) a combination of IR thermography (to obtain surface temperature distributions) and thermocouples (to obtain internal temperature distributions) was used. In these initial investigations a $30 \mathrm{~mm}$ thick Divinycell H100 foam core was used. To facilitate the introduction of the thermocouples, $2 \mathrm{~mm}$ diameter holes were drilled into the core material at various locations; these are shown in Figure 4. To measure the temperature distribution across the specimen width, four holes were drilled through the bottom face sheet to nominal depth of $3 \mathrm{~mm}$ below the upper face sheet and spaced $7.5 \mathrm{~mm}$ apart across the width of the specimen at the midspan. To measure the temperature distribution along the specimen length, a further three holes were drilled at $75 \mathrm{~mm}$ intervals along the specimen length on the width-wise central axis. To measure the through-thickness temperature distribution four more thermocouples were also placed $7.5 \mathrm{~mm}$ apart through the thickness of the core. The holes for these were drilled through the core material from the side of the specimen starting at $3 \mathrm{~mm}$ below the top face sheet to $4.5 \mathrm{~mm}$ from the bottom face sheet, laterally offset by $2.5 \mathrm{~mm}$ across the specimen width. The lateral offset was introduced to reduce the effect of the upper holes on the heat transfer from the top face sheet to lower holes that would occur if all the holes were drilled to the same depth. The temperature measurements from each of the three sets of the thermocouples are shown in Figure 5 for a top surface temperature of $80^{\circ} \mathrm{C}$. It can be seen that the temperature distribution along the specimen length and across the width is practically uniform, with up to $4^{\circ} \mathrm{C}$ difference between the mid-plane and the specimen edge. The temperature distribution through the core thickness is approximately linear.

The through-thickness temperature profile was also assessed using IR images of the specimen side using a Silver $480 \mathrm{M}$ detector with a $320 \times 256$ pixel indium antimonide cooled detector, manufactured by Cedip Infrared Systems. Figure 6 shows the through thickness temperature profile on the specimen side immediately after removal of the insulation, when the top face sheet was heated to $95^{\circ} \mathrm{C}$. Note that the temperature through the $0.9 \mathrm{~mm}$ thick face sheets remains approximately uniform due to the high thermal conductivity of the aluminium. At first the profile through the thickness of the foam is roughly linear as assumed in the 
Palleti, H.N.K.T., Zhang, S., Dulieu-Barton, J.M., Fruehmann, R.K. and Thomsen, O.T., "Influence of thermomechanical interaction effects on the failure behaviour of polymer foam cored sandwich panels”, Journal of Sandwich Structures and Materials, 17, 2015, 308-331. DOI: 10.1177/1099636214567602.

modelling, with a similar through thickness gradient as given by the thermocouples in Figure 5. Over time, the through thickness profile becomes nonlinear due to cooling at the specimen edges. As a result, the temperature distribution across the specimen width becomes nonuniform. Equilibrium was reached roughly 2 minutes after the insulation was removed. As the insulation must be removed to enable the specimen side to be observed for DIC, it is imperative that the loading is conducted quickly while the temperature gradient is still close to linear, preferably in less than 30 seconds. A set of initial tests indicated that failure occurred after no more than $10 \mathrm{~mm}$ displacement. Hence a $20 \mathrm{~mm} / \mathrm{min}$ loading rate was selected to collect the white light images for the DIC.

In summary the following test methodology was defined:

1. The specimen was positioned on the simply supported three-point bending jig. One image of the side surface with a speckle pattern was recorded as the reference position of the specimen.

2. The insulation was positioned at the side surface of the specimen. The top face sheet was heated to the required temperature and held until a steady temperature state was achieved and the specimen was allowed to expand freely under the thermal loading.

3. The insulation was removed on one side to enable images of the specimen deformation to be obtained.

4. The load was applied in displacement control at a rate of $20 \mathrm{~mm} / \mathrm{min}$ until the specimen failed. Images of the specimen side surface with a speckle pattern and the load were recorded at $2 \mathrm{~Hz}$.

\section{Elastic behaviour of sandwich beams at elevated temperatures}

The response of the foam cored sandwich beam assuming linear elastic material properties and including geometric nonlinearity and thermal degradation of the core is analysed using the HSAPT approach discussed previously [15]. In addition, an approximate 2D elastic FE analysis of half of the sandwich beam with symmetry boundary conditions imposed at the mid-span was conducted using the FE analysis software package, ABAQUS/Standard ver. 6.10 [22]. Figure 7 shows the final FE mesh used in the half span beam model, which was the result of an elaborate mesh convergence study. The issues and difficulties concerning the correlation between HSAPT predictions and fully converged nonlinear FE results are discussed in detail by Santiuste et al. [16] and Palleti et al. [28]. Generally it is found that nonlinear FE models that assume linear elastic material behaviour (and infinite straining 
Palleti, H.N.K.T., Zhang, S., Dulieu-Barton, J.M., Fruehmann, R.K. and Thomsen, O.T., "Influence of thermomechanical interaction effects on the failure behaviour of polymer foam cored sandwich panels”, Journal of Sandwich Structures and Materials, 17, 2015, 308-331. DOI: 10.1177/1099636214567602.

capability) but include geometric nonlinearity (i.e. large displacements and moderate rotations) yield predictions that correlate well with HSAPT model results.

In accordance with [16, 28] the nonlinear FE model was based on the following restrictive assumptions:

1. The polymer core material is linear elastic (and implicitly assumed has infinite straining capability) and orthotropic with properties varying with temperature in accordance with $[19,20]$.

2. The face sheets are linear elastic and isotropic, and the material properties are further assumed to be independent of temperature.

3. The roller through which the load is applied to the top face sheet is modelled as a rigid body.

4. The outer support (see Figure 7) is modelled as a vertical (z-direction) displacement constraint applied to a single point on the bottom face sheet, whereas no constraints are imposed in the horizontal direction. (It is important to include the overhang at the beam end to avoid excessive deformations resulting from the approximation of the support as a point constraint.)

5. It is assumed that the face sheets are perfectly bonded to the core.

6. The strain rate is assumed to be sufficiently low so that strain rate effects in the material behaviour of the core can be ignored.

7. Geometric nonlinearity is included in the model.

The FE model is informed with the measured equilibrium temperatures in accordance with the corresponding thermal gradients obtained in the experiments. The thermal gradient is applied only through the core, while the temperature through the thickness of the face sheet is assumed to be uniform in accordance with the temperature field measured at the specimen edge using the IR detector, as shown in Figure 6. Furthermore, the variation of temperature is assumed be constant across the width and along the length of the beam. The FE model contains 4 elements through the face sheet thickness and 20 elements through the core thickness. 8-noded plane stress quadratic elements with reduced integration (CPS8R) are used. Mesh refinement is provided in the vicinity of load introduction at mid-span and near the supports (as shown in Figure 7). A mesh convergence study was performed demonstrating convergence (stiffness - peak displacements) when a total of 6256 elements are used with 736 elements in each face sheet and 4784 elements in the core. The first step is to assess the 
Palleti, H.N.K.T., Zhang, S., Dulieu-Barton, J.M., Fruehmann, R.K. and Thomsen, O.T., "Influence of thermomechanical interaction effects on the failure behaviour of polymer foam cored sandwich panels”, Journal of Sandwich Structures and Materials, 17, 2015, 308-331. DOI: 10.1177/1099636214567602.

accuracy of the geometrically linear and linear elastic FE model by comparing its predictions with experimental results. It has already been established that converged geometrically nonlinear and elastic FE models provide predictions that are in excellent agreement with HSAPT model predictions [16, 28]. Accordingly, the main emphasis in the following discussion will be on the experimental observations and their correlation with nonlinear FE results.

Figure 8 shows the measured deflections of the top face sheet at mid-span vs. applied load at three upper face sheet temperatures of $25^{\circ} \mathrm{C}, 50^{\circ} \mathrm{C}$ and $70^{\circ} \mathrm{C}$. The bottom face sheet is at $25^{\circ} \mathrm{C}$ in all these cases. It is observed that the initial sandwich beam bending stiffness predicted by the FE analysis matches the experimentally obtained stiffness for all the three upper face sheet temperatures. However, in the experiments it is seen that the load vs. deflection of the top face sheet at mid-span relation displays a linear trend until the load suddenly drops. The reason for this is that face sheet indentation and core crushing occurred followed by face-core debonding, as depicted in Figure 9 for a sandwich beam specimen subjected to a temperature of $50^{\circ} \mathrm{C}$. Thus, the nonlinear behaviour predicted by HSAPT (driven by geometric nonlinearity combined with a reduction of core stiffness with increasing temperature), was in all cases preceded by face sheet indentation and core crushing triggered by nonlinear material behaviour (plasticity). This behaviour cannot be captured by the geometrically nonlinear/elastic (with infinite straining capability) FE analyses. Here a linear load-deflection behaviour is predicted until distinctly nonlinear response characteristics are observed for a top face sheet mid-span deflection of around $20 \mathrm{~mm}$. The nonlinearity is associated with the formation of local mid-span wrinkles in the upper face sheet as the core material softens due to the increasing temperature and loses its ability to support the face sheet. Figure 10 shows that top face sheet wrinkling is even predicted to occur at room temperature $\left(25^{\circ} \mathrm{C}\right)$ and without a through-thickness thermal gradient but for very large displacements. The wrinkle deformation results in a complete loss of the load carrying capability of the upper face sheet that is stabilized through and by the core, which leads to a progressive loss of overall sandwich beam bending stiffness with increasing mid-span load. The behaviour is in close agreement with HSAPT predictions [15], and if the nonlinear FE solution procedure is continued by additional load increments, the geometrically nonlinear/elastic HSAPT and FE solutions will eventually predict loss of stability (reduction in stiffness). Comparing the experimental observations with the geometrically nonlinear/elastic FE results it is seen that indentation failure occurred at less than $25 \%$ of the 
Palleti, H.N.K.T., Zhang, S., Dulieu-Barton, J.M., Fruehmann, R.K. and Thomsen, O.T., "Influence of thermomechanical interaction effects on the failure behaviour of polymer foam cored sandwich panels”, Journal of Sandwich Structures and Materials, 17, 2015, 308-331. DOI: 10.1177/1099636214567602.

load at which a nonlinear load response is predicted. Hence, to provide numerical predictions that capture the failure mode, load response and failure load accurately, it is necessary to include material nonlinearity in the FE modelling.

Interestingly, a comparison of the mid-span deflections at different temperatures for a midspan load of $800 \mathrm{~N}$ shows a very similar trend between the predictions of both the FE and HSAPT model and the experimental observations see Figure 11. At this mid-span load, the sandwich constituent materials are still within the elastic limit. The top face sheet mid-span deflection is measured relative to the room temperature equilibrium condition and therefore includes the deflection/deformation due to thermal expansion. Hence, as the temperature of the top face sheet is increased from 25 to $70^{\circ} \mathrm{C}$ while maintaining the bottom face sheet at $25^{\circ} \mathrm{C}$, a decrease in the top-face sheet displacement is recorded. Then at $90^{\circ} \mathrm{C}$ there is a sudden increase in displacement. However, the situation at $90^{\circ} \mathrm{C}$ is further complicated by effects of crossing the glass transition temperature of the PVC foam. For this reason, the current work has focused only on tests conducted up to $70^{\circ} \mathrm{C}$.

\section{Influence of core and face sheet material nonlinearity on sandwich beam behaviour at room temperature $\left(25^{\circ} \mathrm{C}\right)$}

The FE model described in section 4 is extended by the inclusion of material nonlinearity through the adoption of Hill's anisotropic plasticity theory [22], and by representing the multi-axial stress-strain behaviour of the polymer core and face sheet materials by multilinear approximations of the stress-strain curves, as described in section 2. The converged FE mesh, loading and boundary conditions remain as shown in Figure 7.

The comparison of the fully nonlinear FE model predictions, that includes both geometric and material nonlinearity, with the experimental results has been conducted only for room temperature $\left(25^{\circ} \mathrm{C}\right)$ as accurate material properties at elevated temperatures are not available for the foam core. The comparison is shown for both the top and bottom face sheet displacements in Figure 12. The FE model is seen to slightly under predict the stiffness and ultimate load, but the discrepancy in the ultimate load is only $4.8 \%$ relative to the experimental value and 5.1\% w.r.t. the predicted initial stiffness. Also, the predicted failure mode, i.e. crushing of the core and corresponding indentation involving extensive face sheet plasticity, agrees well with the experimental observations, and also the predicted indentation depth (see image in Figure 9) agrees well with the experimental results as can be seen in 
Palleti, H.N.K.T., Zhang, S., Dulieu-Barton, J.M., Fruehmann, R.K. and Thomsen, O.T., "Influence of thermomechanical interaction effects on the failure behaviour of polymer foam cored sandwich panels”, Journal of Sandwich Structures and Materials, 17, 2015, 308-331. DOI: 10.1177/1099636214567602.

Figure 12. The deformation field obtained from the nonlinear FE model, verifying the observed indentation behaviour, is shown in Figure 13.

The influence of the core and face sheet material nonlinearity on the load-deflection behaviour at room temperature $\left(25^{\circ} \mathrm{C}\right)$ at mid-span of the upper face sheet is provided in Figure 14. It can be seen that the nonlinear elasto-plastic FE model shows excellent correspondence with the experimental data. When the material nonlinearity of the face sheet material is included in the modelling, but the core is assumed to be linear elastic, it is observed that the load at which significant nonlinear behaviour initiates reduces by about $50 \%$ compared to the nonlinear/elastic FE predictions (from roughly $4000 \mathrm{~N}$ to $2000 \mathrm{~N}$ ). When the face sheets are considered to behave linear elastically and the core material nonlinearity/plasticity is included the load where the response changes from being linear to distinctly nonlinear reduces to about $1000 \mathrm{~N}$ and a peak load (failure load) of about $1300 \mathrm{~N}$ is obtained. This is very close to the experimental observations and the predictions of the fully nonlinear elasto-plastic FE model results (long dashed lines) which show a transition from linear to nonlinear response at a load of roughly $1000 \mathrm{~N}$ and a peak (failure) load of about $1100 \mathrm{~N}$. The results clearly indicate that failure is dominated by the through-thickness normal stress in the core. Moreover, the comparative analysis results presented in Figure 14 also highlights that the nonlinear interaction effects, driven by geometric nonlinearity that cause a progressive loss of stiffness (and which may lead to loss of stability), predicted by the HSAPT model greatly exceed the loads that can be sustained by typical engineering materials and typical sandwich beam geometries. In other words, the limits of material elasticity (in both the core and the face sheets) are reached long before geometric nonlinearity becomes an issue for the considered three-point bending example.

\section{Discussion and Conclusions}

An experimental methodology has been developed that allows the simultaneous application of mechanical loading and a well defined thermal field (homogeneous in length and width directions and with a linear gradient through the thickness). DIC was used to assess the local displacement field of the sandwich beam and the temperature was monitored using an infrared detector and thermocouples. A series of three experiments has been conducted for a foam cored sandwich beam with aluminium face sheets, and the experimental observations have been compared with numerical results obtained using nonlinear FE analysis as well as 
Palleti, H.N.K.T., Zhang, S., Dulieu-Barton, J.M., Fruehmann, R.K. and Thomsen, O.T., "Influence of thermomechanical interaction effects on the failure behaviour of polymer foam cored sandwich panels”, Journal of Sandwich Structures and Materials, 17, 2015, 308-331. DOI: 10.1177/1099636214567602.

analytical results based on the so-called High-Order Sandwich Panel Theory (HSAPT) [12, $15,16]$.

It has been demonstrated, for the case of a foam cored sandwich beam in three-point bending, that making similar assumptions regarding the material models (i.e. assuming linear elastic material behaviour and unlimited straining capability), the FE and HSAPT models compare very closely. The comparison of the FE model with experiments thereby demonstrates that the key short coming of the HSAPT model, as presented in e.g. [15], lies in its inherent assumptions regarding linear elasticity and unlimited straining capability of the materials. For the case considered, three interacting failure modes which lead to the final collapse of the sandwich beam are observed from the experiments: failure (yielding) of the top face sheet, failure (yielding) of the core and failure (debonding) of the interface. By considering the face sheets and the core in turn, it has been shown that both materials are expected to fail at much smaller loads/deflections than those required to provoke the predicted geometrically driven nonlinearity.

The nonlinear thermomechanical interaction effects, which may change a linear and stable load response of a sandwich structure into becoming nonlinear and unstable as predicted by the HSAPT models $[12,15,16]$, have been shown to be very difficult to trigger in a laboratory test setup involving the application of localised/concentrated mechanical loading and thermally induced deformations. Thus, in all the experiments, failure of the core dominated. This can be ascribed to two aspects of the chosen three-point bending test configuration. On the one hand, the geometry of the specimen (length to thickness ratio) favours the core shear failure mode. On the other hand the concentrated through-thickness load at mid-span in the three point test will promote compressive failure (crushing) of the core, inducing localised face sheet yielding. For this reason, most sandwich structures are designed to sustain a combination of in-plane and distributed lateral loads. Through-thickness point loading, as applied in the three-point bend test, is typically avoided either combined with some means of spreading the load, by means of inserting a local reinforcement of the face sheet.

It is shown that nonlinear thermomechanical interaction effects in foam cored sandwich structures leading to the risk of loss of stability, especially at elevated temperatures, can and do indeed occur in realistic shell or plate sandwich structures subjected to distributed pressure loading (which is the typical loading type for which sandwich structures are designed). 
Palleti, H.N.K.T., Zhang, S., Dulieu-Barton, J.M., Fruehmann, R.K. and Thomsen, O.T., "Influence of thermomechanical interaction effects on the failure behaviour of polymer foam cored sandwich panels”, Journal of Sandwich Structures and Materials, 17, 2015, 308-331. DOI: 10.1177/1099636214567602.

Furthermore the nonlinear behaviour in most realistic cases will involve some influence of material nonlinearity, even for the case with smoothly distributed external loading. Accordingly, a realistic prediction of the complex nonlinear response of thermomechanically loaded foam cored sandwich structures must include the interactions between geometric nonlinearity, material nonlinearity, thermally induced deformations and degradation/reduction of the material properties at elevated temperatures. The HSAPT approach in principle can be expanded to account for this, and it would be valuable to further develop this approach at least for some bench mark cases, albeit the mathematical complexity in doing so will be considerable. For more general cases, converged fully nonlinear FE solution procedures are likely to provide more easily attainable and reproducible predictive results.

Model predictions involving very complex thermomechanical interaction effects should be validated through experiments. In doing so, and with the objective of triggering a load response that displays significant influence of geometric nonlinearity and thermomechanical interaction effects, a realistic test should be designed so that distributed mechanical loading can be imposed in a well defined manner along with well defined geometric boundary conditions and a well defined thermal field.

\section{Acknowledgements}

The work presented was co-sponsored by the Danish Council for Independent Research | Technology and Production Sciences (FTP), Grant Agreement 274-08-0488, “Thermal Degradation of Polymer Foam Cored Sandwich Structures”, the Chinese Scholarship Council, and the US Navy, Office of Naval Research (ONR), Grant Award N000140710227. The ONR programme manager was Dr. Yapa D. S. Rajapakse. The financial support received is gratefully acknowledged.

The authors are grateful to DIAB for providing the foam core material used in this paper and for their input into the project.

The compressive testing of PVC H100 foam core material leading to a full stress-strain curve to failure used in this work was conducted by S.T. Taher, Department of Mechanical and Manufacturing Engineering, Aalborg University, Denmark. 
Palleti, H.N.K.T., Zhang, S., Dulieu-Barton, J.M., Fruehmann, R.K. and Thomsen, O.T., "Influence of thermomechanical interaction effects on the failure behaviour of polymer foam cored sandwich panels”, Journal of Sandwich Structures and Materials, 17, 2015, 308-331. DOI: 10.1177/1099636214567602.

\section{References}

1. Najafizadeh M.M., Heydari H.R., 2004, Thermal buckling of functionally graded circular plates based on higher order shear deformation plate theory. European Journal of Mechanics - A/Solids, 23(6):1085-1100.

2. Dafedar J., Desai Y., 2002, Thermomechanical buckling of laminated composite plates using mixed, higher-order analytical formulation. Journal of Applied MechanicsTransactions of the Asme, 69(6):790-799.

3. Kapuria S., Achary G., 2004, An efficient higher order zigzag theory for laminated plates subjected to thermal loading RID C-5368-2008. Int J Solids Structures, 41(16-17):46614684.

4. Shiau L., Kuo S., 2004, Thermal postbuckling behavior of composite sandwich plates. J Eng Mech, 130(10):1160-1167.

5. Matsunaga H., 2005, Thermal buckling of cross-ply laminated composite and sandwich plates according to a global higher-order deformation theory. Composite Structures, 68(4):439-454.

6. Dawe D.J., 2002, Use of the finite strip method in predicting the behaviour of composite laminated structures. Composite Structures, 57(1-4):11-36.

7. Cooke G.M.E., 2004, Stability of lightweight structural sandwich panels exposed to fire. Fire Mater, 28(2-4):299-308.

8. Frostig Y., 1997, Hygothermal (environmental) effects in high-order bending of sandwich beams with a flexible core and a discontinuous skin. Composite Structures, 37(2):205-221.

9. Frostig Y., Baruch M., 1993, High-order buckling analysis of sandwich beams with transversely flexible core. J Eng Mech, 119(3):476-495.

10. Sokolinsky V., Frostig Y., 2000, Branching behavior in the nonlinear response of sandwich panels with a transversely flexible core. Int J Solids Structures, 37(40):57455772.

11. Frostig Y., Thomsen O.T., 2005, Localized effects in the nonlinear behavior of sandwich panels with a transversely flexible core. Journal of Sandwich Structures and Materials, 7(1):53-75

12. Frostig Y., Thomsen O.T., 2008, Thermal buckling and postbuckling of sandwich panels with a transversely flexible core. AIAA J, 46(8):1976-1989. 
Palleti, H.N.K.T., Zhang, S., Dulieu-Barton, J.M., Fruehmann, R.K. and Thomsen, O.T., "Influence of thermomechanical interaction effects on the failure behaviour of polymer foam cored sandwich panels”, Journal of Sandwich Structures and Materials, 17, 2015, 308-331. DOI: 10.1177/1099636214567602.

13. Frostig Y., Thomsen O.T., Sheinman I., 2005, On the nonlinear high-order theory of unidirectional sandwich panels with a transversely flexible core. Int. J Solids Structures, 42(5-6):1443-1463.

14. Frostig Y., Thomsen O.T., 2007, Buckling and nonlinear response of sandwich panels with a compliant core and temperature dependent mechanical properties. J Mech Mater Struct, 2(7):1355-1380.

15. Frostig Y., Thomsen O.T., 2008, Nonlinear thermal response of sandwich panels with a flexible core and temperature dependent mechanical properties. Composites Part BEngineering 39(1):165-184.

16. Santiuste C., Thomsen O.T., Frostig Y., 2011, Thermomechanical load interactions in foam cored axi-symmetric sandwich circular plates - High-order and FE models. Composite Structures, 93(2): 369-376.

17. Robinson A., Dulieu-Barton J.M., Quinn S., Burguete R., 2013, The potential for assessing residual stress using thermoelastic stress analysis: a study of cold expanded holes. Experimental Mechanics, accepted, in press. .

18. Sutton M.A., Orteu J.-J., Schreier H.W., 2009, Image correlation for shape, motion and deformation measurements. Springer Science and Business Media, New York.

19. Zhang S., Dulieu-Barton J.M., Fruehmann R.K., Thomsen O.T., 2012, A methodology for obtaining material properties of polymeric foam at elevated temperatures. Experimental Mechanics, 52(1):3-15.

20. Zhang S., Dulieu-Barton J.M., Thomsen O.T., 2015, The effect of temperature on the failure modes of polymer foam cored sandwich structures. Composite Structures, 121, 104-113.

21. Taher S.T., Thomsen O.T., Dulieu-Barton J.M., Zhang S., 2011, Determination of mechanical properties of PVC foam using a modified Arcan fixture. Composites Part A: Applied Science and Manufacturing, 43(10): 1698-1708.

22. Abaqus 6.10 theory manual (PDF Documentation), Chapter 4 Material constitutive theories - Stress potential for anisotropic metal plasticity, pp 4.3.3-1 - 4.3.3-3

23. Wilson A.J.C., 1941, The thermal expansion of aluminium from $0^{\circ}$ to $650^{\circ} \mathrm{C}$. Proceedings of the Physical Society 53(3): 235.

24. DIAB datasheet. http://www.diabgroup.com/Sandwich-technology/Datasheets. Accessed on $09 / 2012$. 
Palleti, H.N.K.T., Zhang, S., Dulieu-Barton, J.M., Fruehmann, R.K. and Thomsen, O.T., "Influence of thermomechanical interaction effects on the failure behaviour of polymer foam cored sandwich panels”, Journal of Sandwich Structures and Materials, 17, 2015, 308-331. DOI: 10.1177/1099636214567602.

25. Hill R., 1948, A theory of yielding and plastic flow of anisotropic metals, Proceedings of the Royal Society of London Series A: Mathematical and Physical Sciences, 193(1033):281-297.

26. Bauschinger J., 1881, Über die Veränderung der Elastizitätsgrenze und des Elastizitätsmoduls Verschiedener Metalle. Zivil ingenieur, 27:289-317.

27. LAVision. http://www.lavision.de/en/products/davis.php. Accessed on 09/2012

28. Palleti H.N.K.T., Thomsen O.T., Dulieu-Barton J.M., Frostig Y., Thermomechanical interactions in polymer foam cored sandwich panels - correlation between high-order sandwich panel theory and finite element analysis results. submitted. 
Palleti, H.N.K.T., Zhang, S., Dulieu-Barton, J.M., Fruehmann, R.K. and Thomsen, O.T., "Influence of thermomechanical interaction effects on the failure behaviour of polymer foam cored sandwich panels”, Journal of Sandwich Structures and Materials, 17, 2015, 308-331. DOI: 10.1177/1099636214567602.

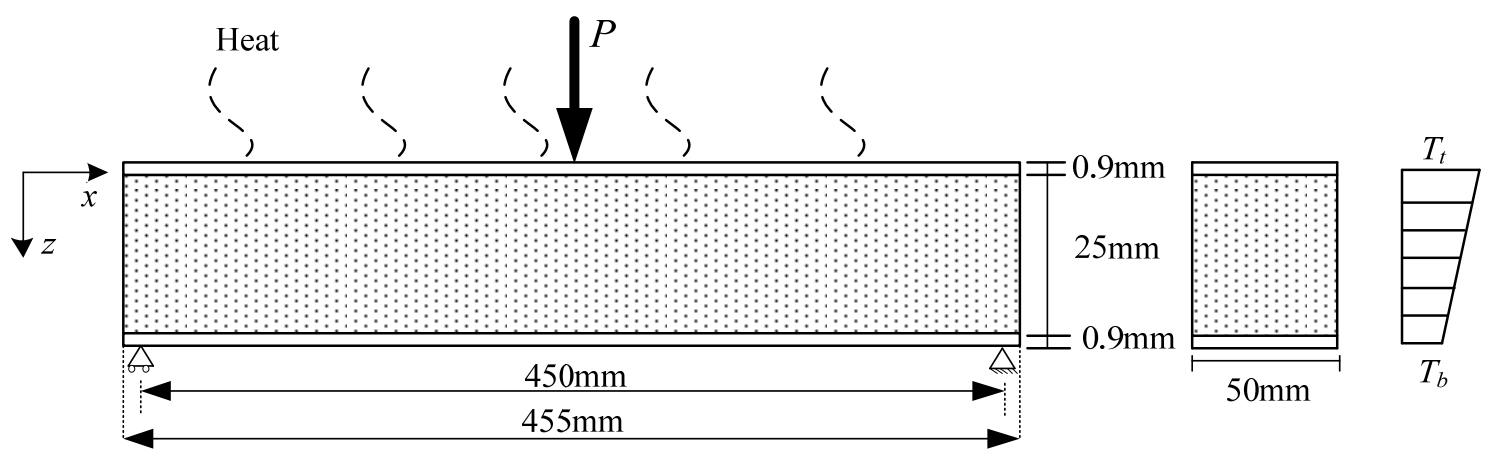

(a)

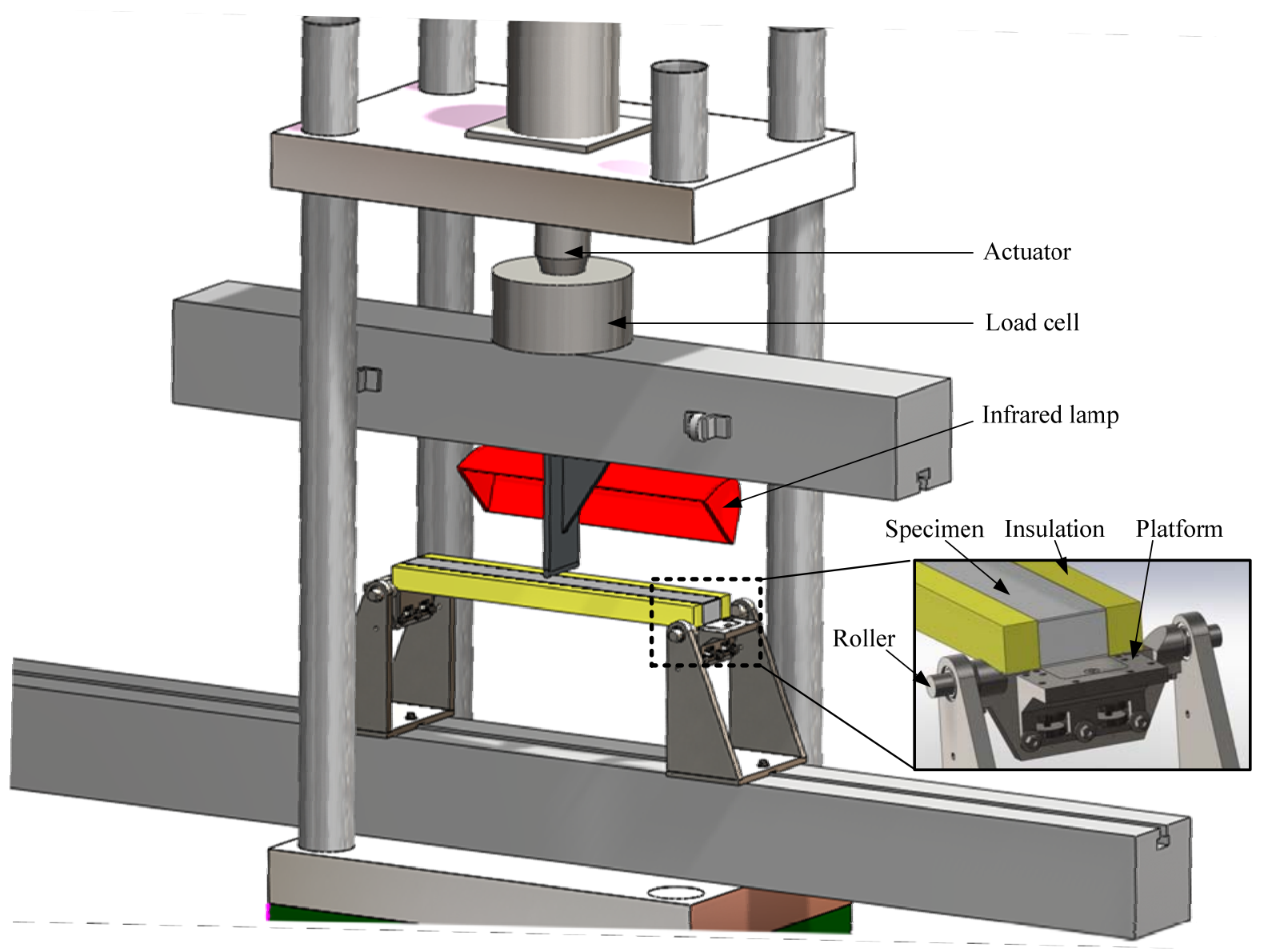

(b)

Figure 1: (a) Specimen loading configuration showing mechanical and thermal boundary conditions; (b) schematic of the experimental set-up. 
Palleti, H.N.K.T., Zhang, S., Dulieu-Barton, J.M., Fruehmann, R.K. and Thomsen, O.T., "Influence of thermomechanical interaction effects on the failure behaviour of polymer foam cored sandwich panels”, Journal of Sandwich Structures and Materials, 17, 2015, 308-331. DOI: 10.1177/1099636214567602.

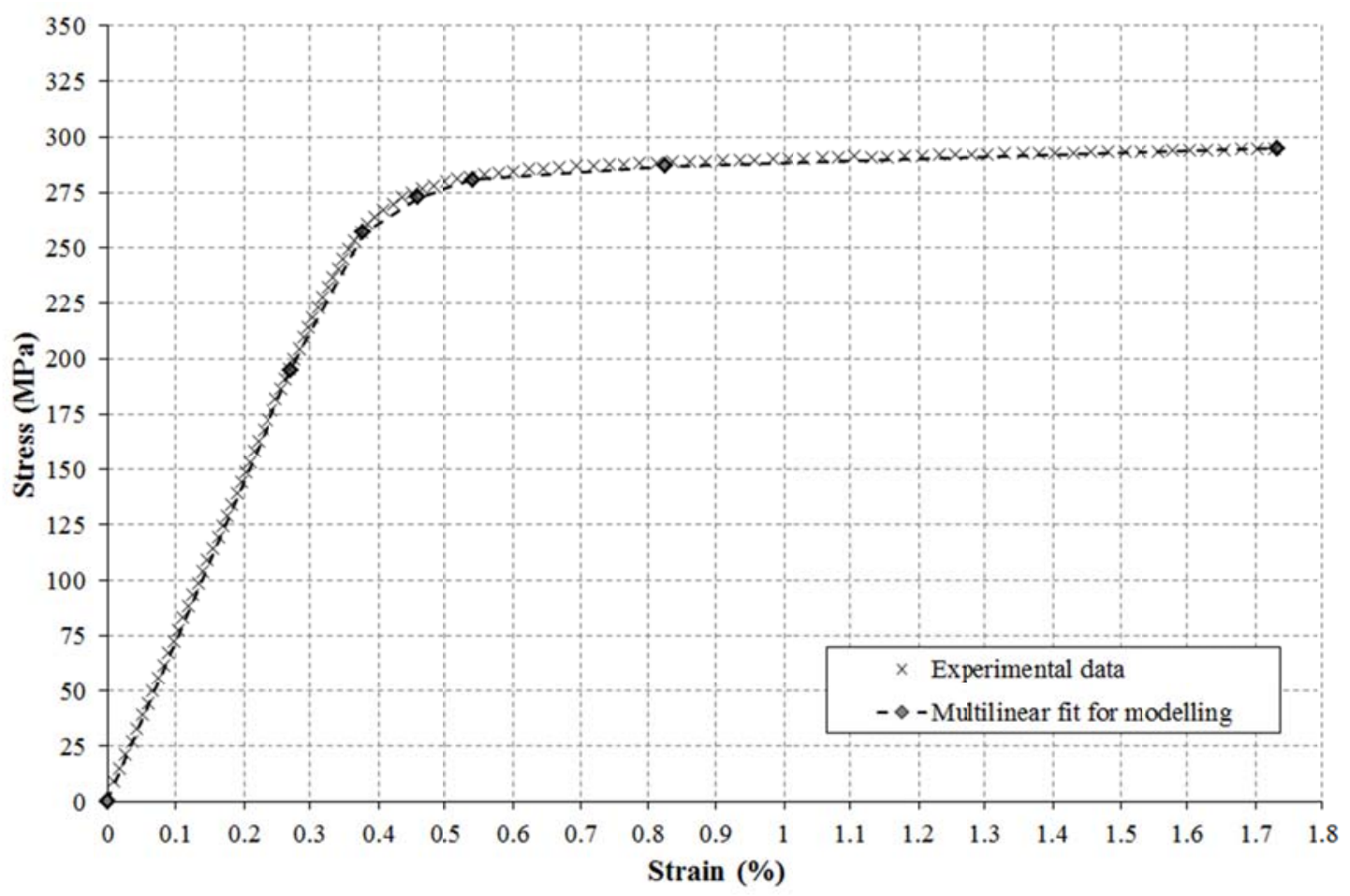

(a)

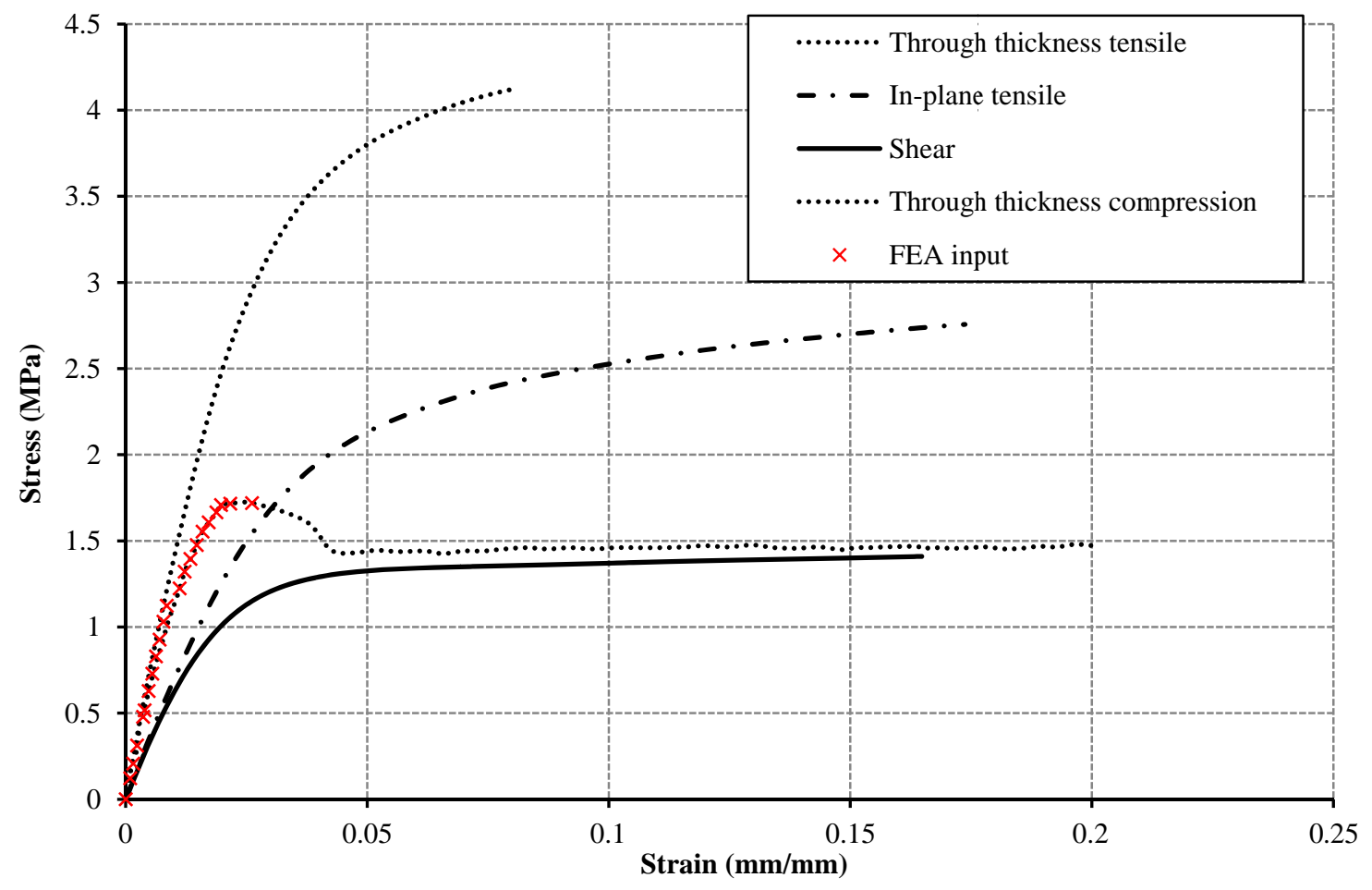

(b)

Figure 2: Stress-strain data for (a) AA6082-T6 aluminium alloy under tension and (b) Divinycell $\mathrm{H} 100$ foam at $25^{\circ} \mathrm{C}$ under tension and shear according to [21]. 
Palleti, H.N.K.T., Zhang, S., Dulieu-Barton, J.M., Fruehmann, R.K. and Thomsen, O.T., "Influence of thermomechanical interaction effects on the failure behaviour of polymer foam cored sandwich panels”, Journal of Sandwich Structures and Materials, 17, 2015, 308-331. DOI: 10.1177/1099636214567602.

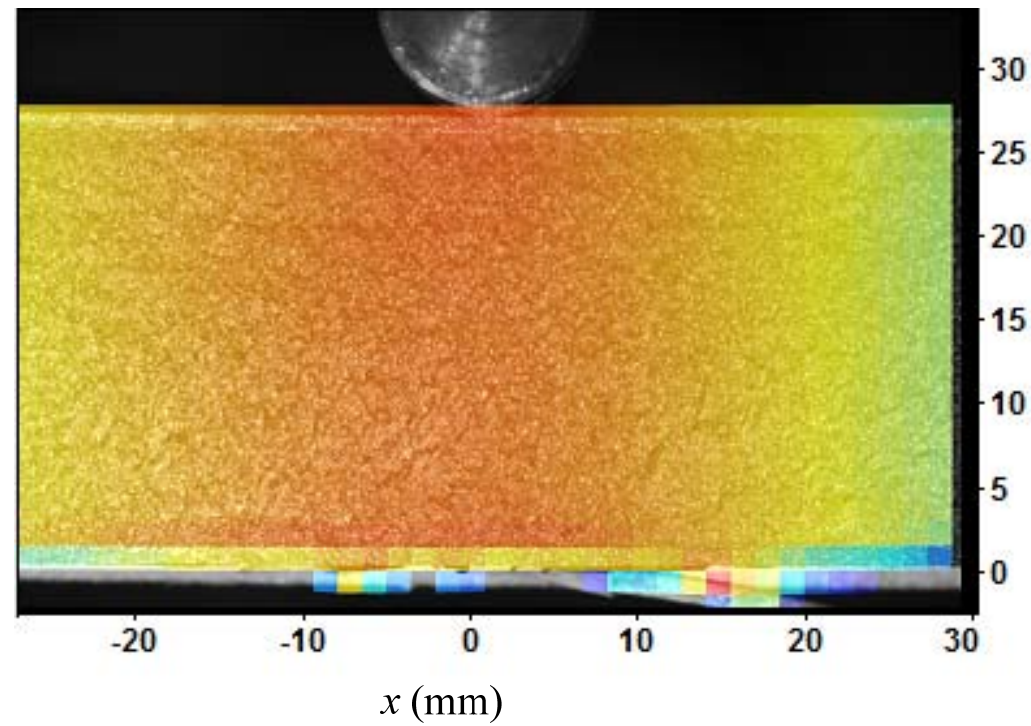

1.275

1.250

1.225

छ 1.200

$N$

$\underbrace{\text { छ }}_{3^{N}}$

Figure 3: A displacement field obtained by DIC in the elastic region. 
Palleti, H.N.K.T., Zhang, S., Dulieu-Barton, J.M., Fruehmann, R.K. and Thomsen, O.T., "Influence of thermomechanical interaction effects on the failure behaviour of polymer foam cored sandwich panels”, Journal of Sandwich Structures and Materials, 17, 2015, 308-331. DOI: 10.1177/1099636214567602.
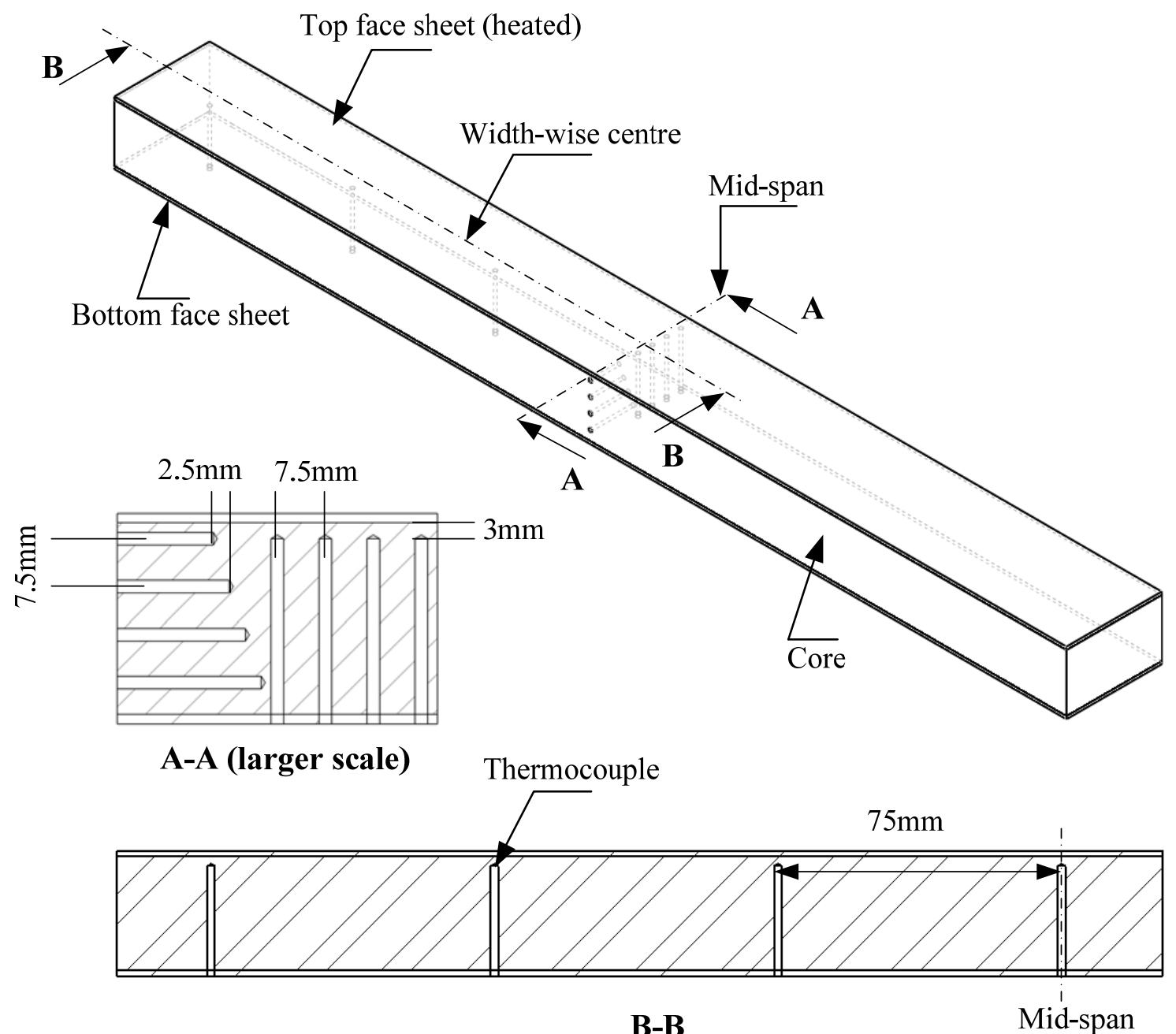

Figure 4: Arrangement of thermocouples across the specimen width, length and thickness. 
Palleti, H.N.K.T., Zhang, S., Dulieu-Barton, J.M., Fruehmann, R.K. and Thomsen, O.T., "Influence of thermomechanical interaction effects on the failure behaviour of polymer foam cored sandwich panels”, Journal of Sandwich Structures and Materials, 17, 2015, 308-331. DOI: 10.1177/1099636214567602.
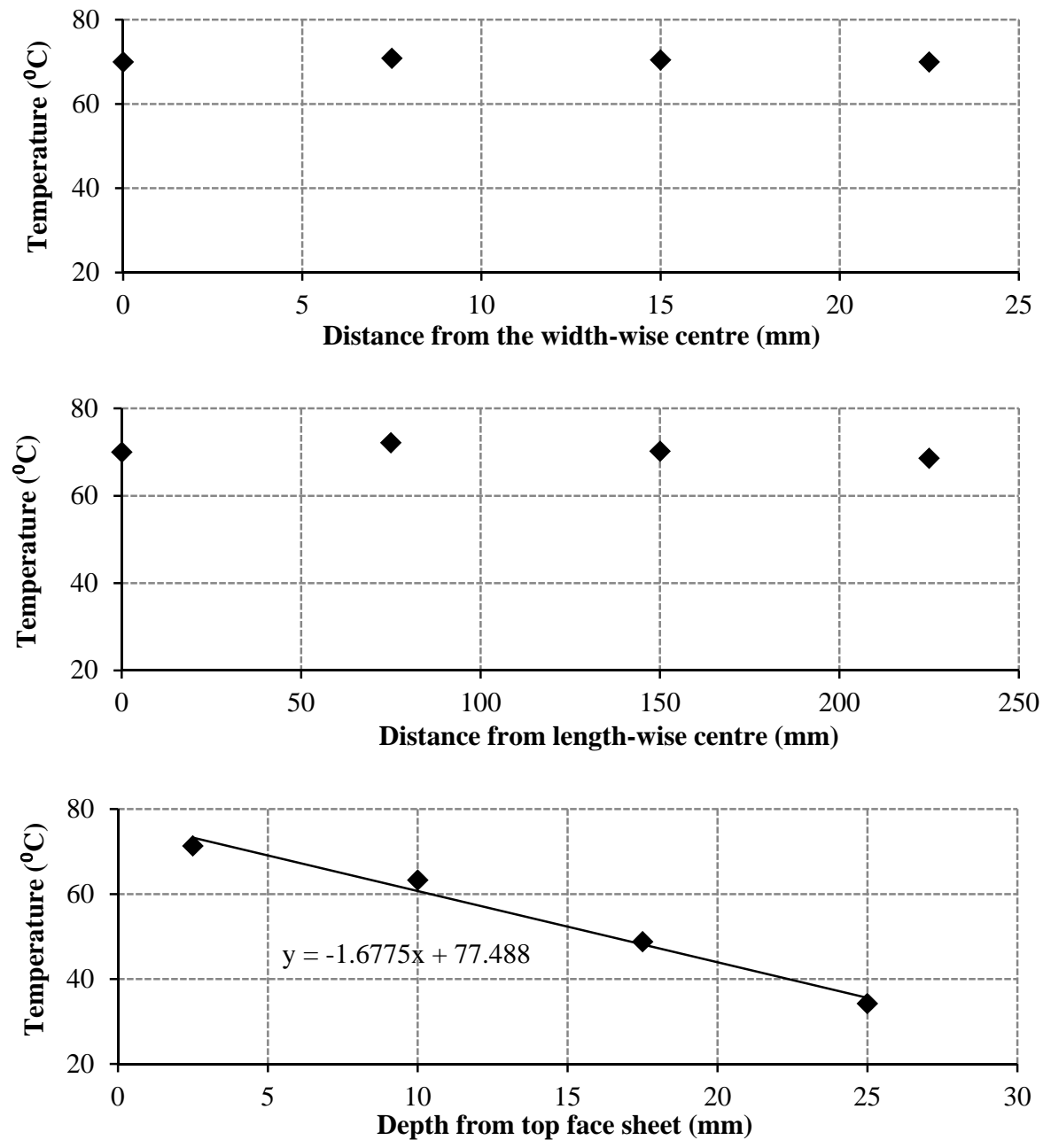

Figure 5: Temperature distribution across the specimen width, length and thickness measured by thermocouples. 
Palleti, H.N.K.T., Zhang, S., Dulieu-Barton, J.M., Fruehmann, R.K. and Thomsen, O.T., "Influence of thermomechanical interaction effects on the failure behaviour of polymer foam cored sandwich panels”, Journal of Sandwich Structures and Materials, 17, 2015, 308-331. DOI: 10.1177/1099636214567602.

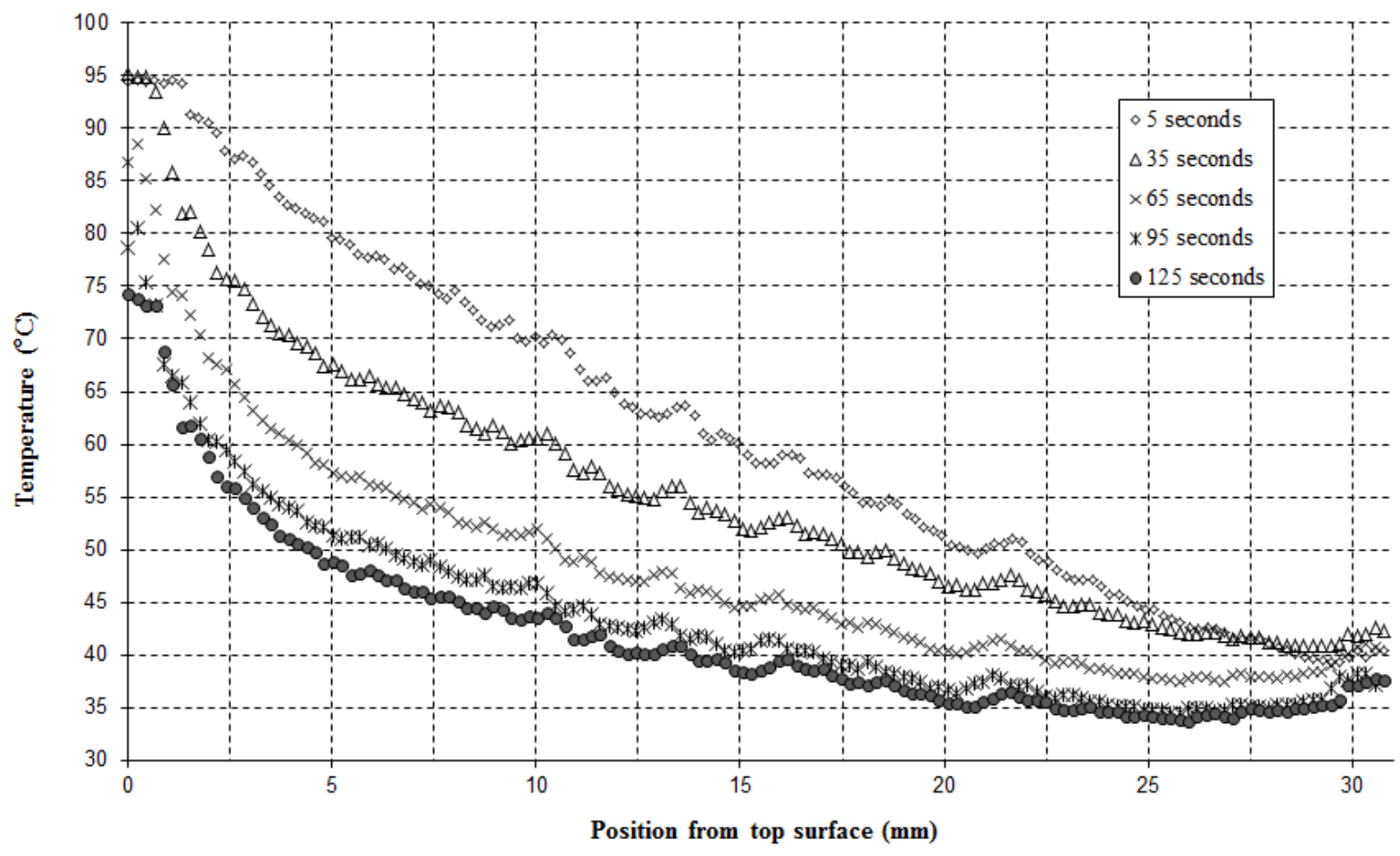

Figure 6: Decay of surface temperature after removal of side insulation (data from IR thermography).

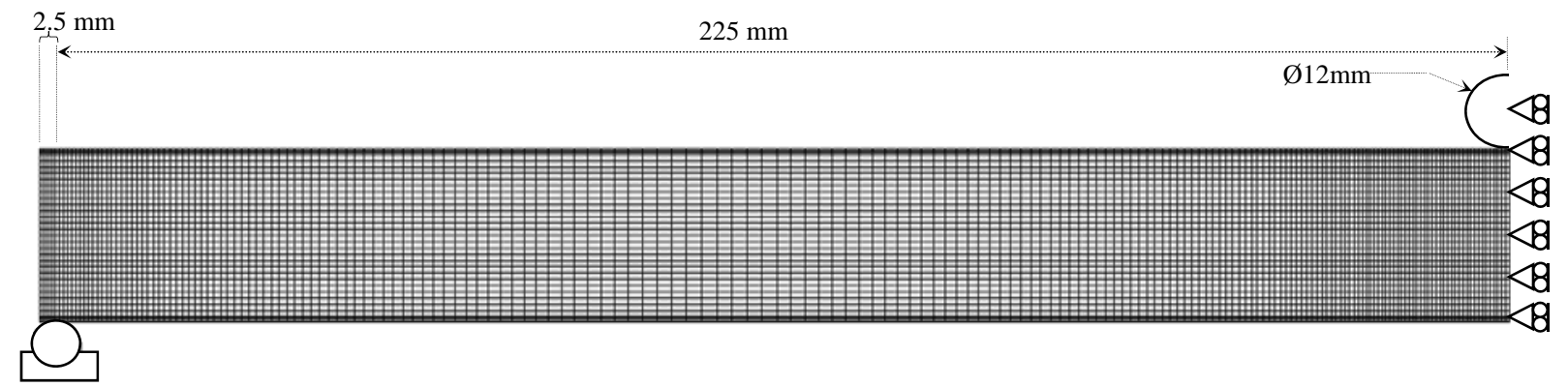

Figure 7: FE model of simply supported sandwich beam subjected to mid-span point load. 
Palleti, H.N.K.T., Zhang, S., Dulieu-Barton, J.M., Fruehmann, R.K. and Thomsen, O.T., "Influence of thermomechanical interaction effects on the failure behaviour of polymer foam cored sandwich panels”, Journal of Sandwich Structures and Materials, 17, 2015, 308-331. DOI: 10.1177/1099636214567602.

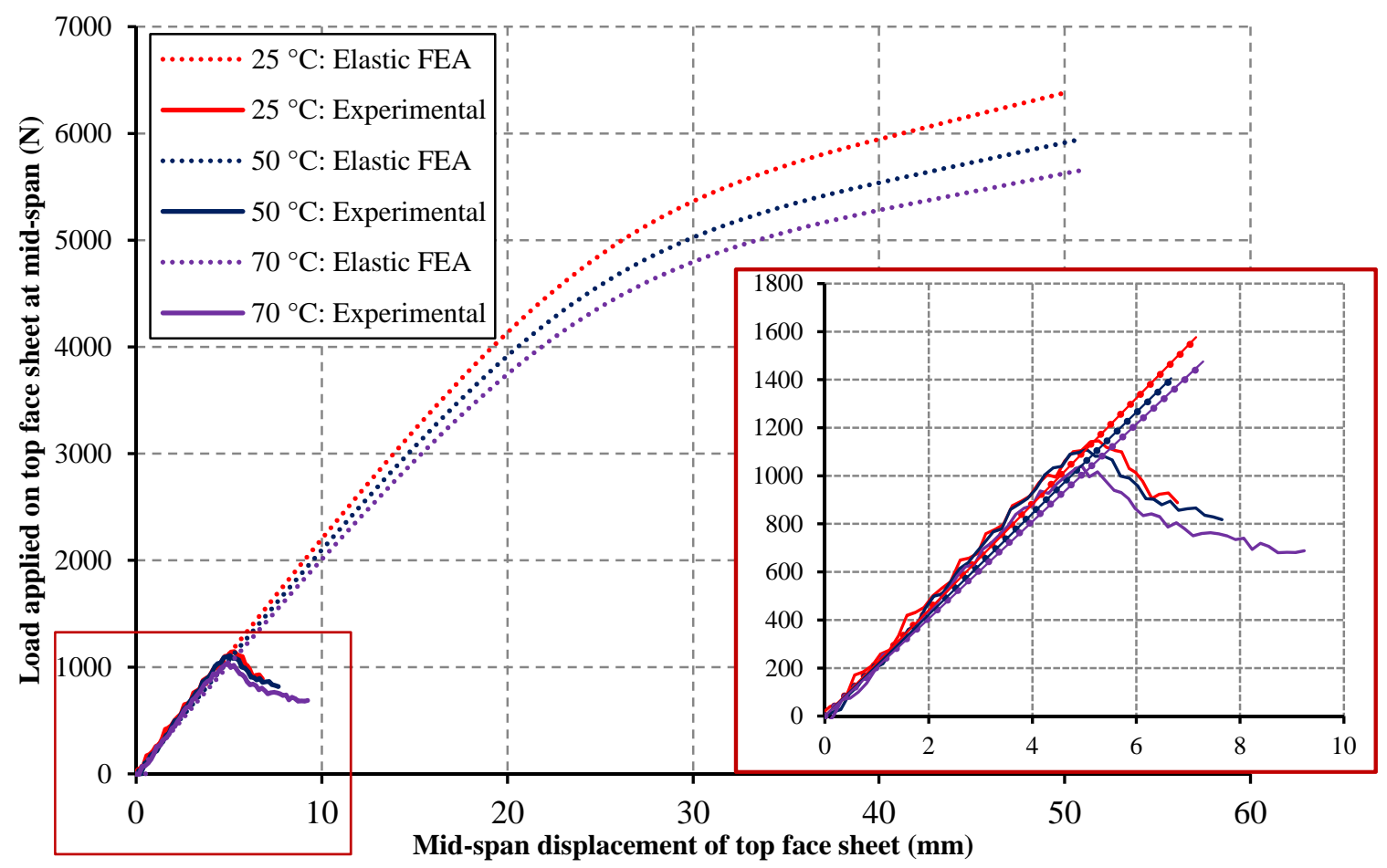

Figure 8: Top face sheet load-deflection curves comparing experimental and elastic FE results.

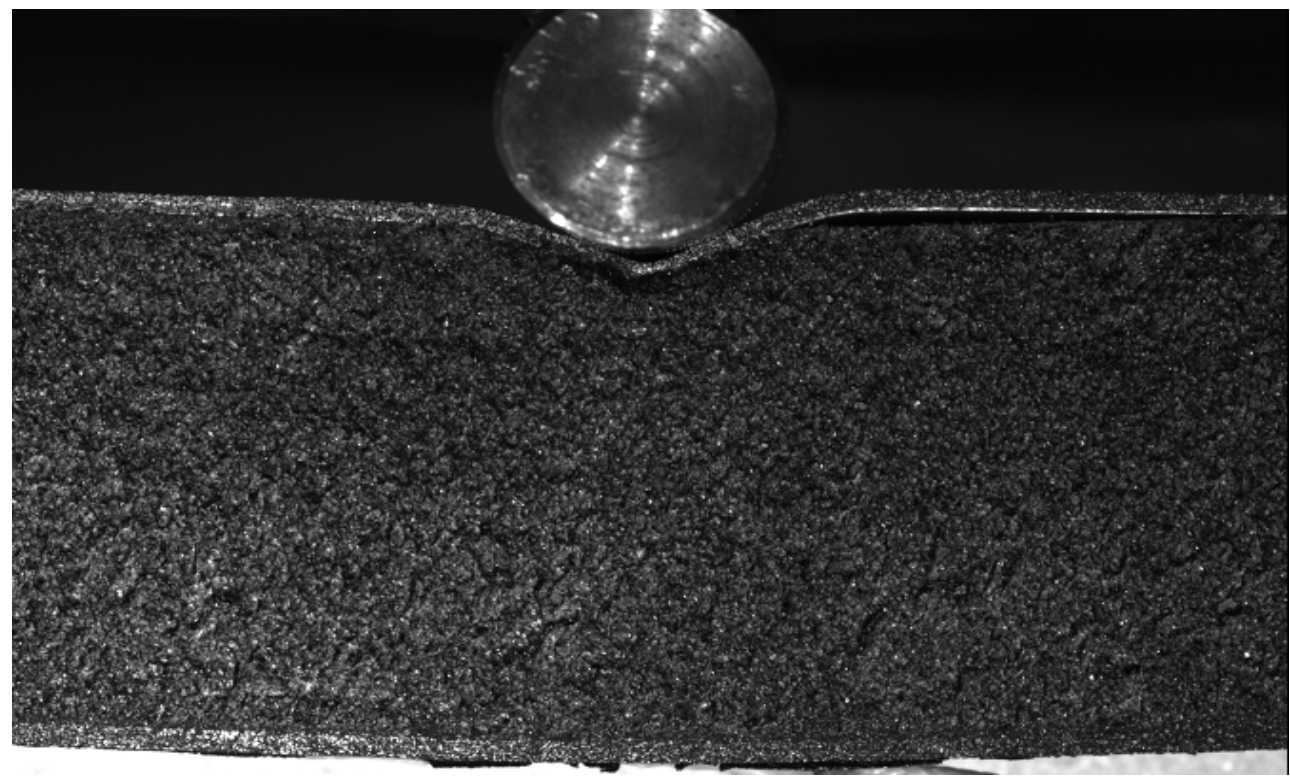

Figure 9: Image of indentation zone in failed sandwich beam specimen subjected to a temperature of $50^{\circ} \mathrm{C}$ on the top face sheet and $25^{\circ} \mathrm{C}$ on the bottom face sheet. 
Palleti, H.N.K.T., Zhang, S., Dulieu-Barton, J.M., Fruehmann, R.K. and Thomsen, O.T., "Influence of thermomechanical interaction effects on the failure behaviour of polymer foam cored sandwich panels”, Journal of Sandwich Structures and Materials, 17, 2015, 308-331. DOI: 10.1177/1099636214567602.

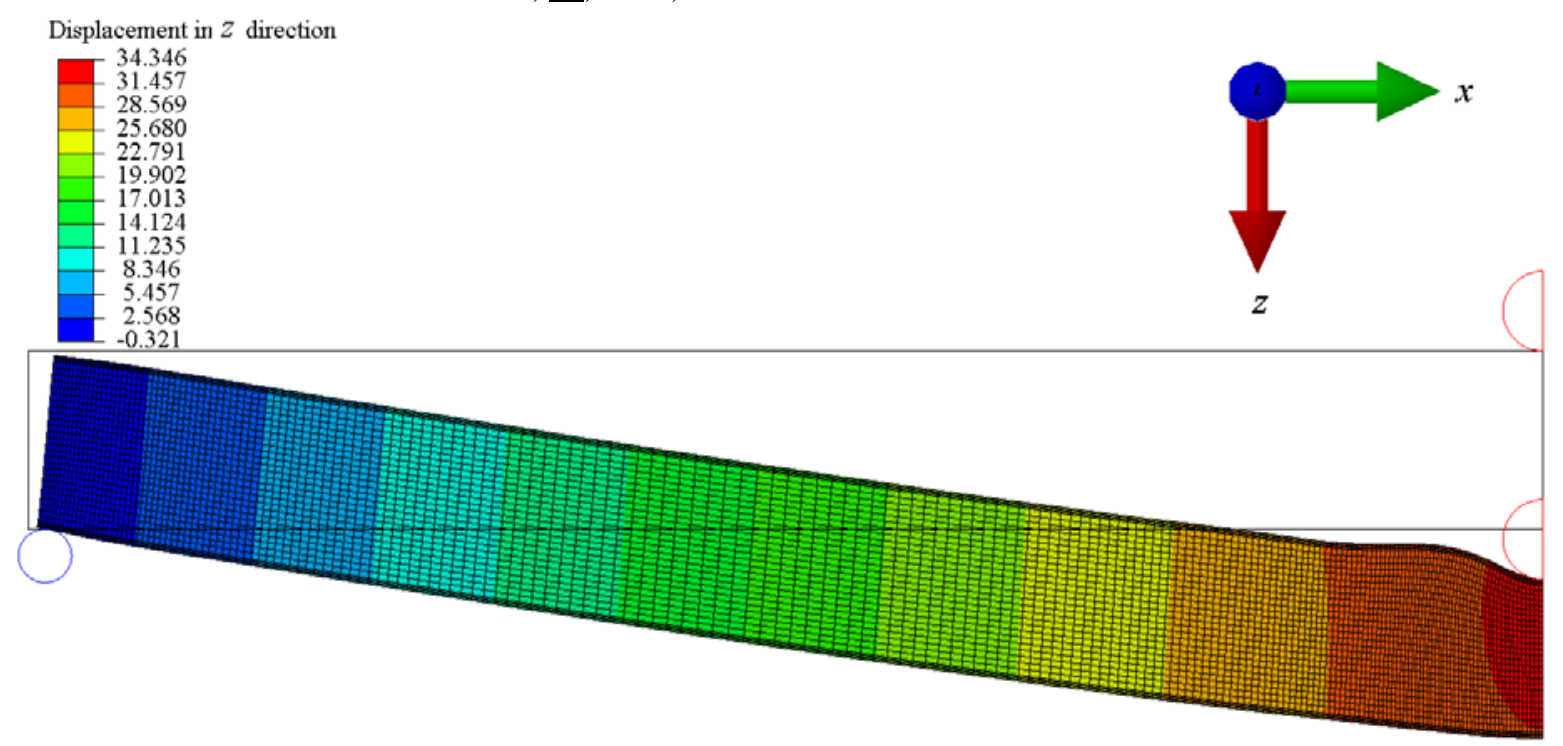

Figure 10: Deformation of elastic FE model at $25^{\circ} \mathrm{C}$ (no thermal gradient along thickness of beam) showing wrinkling-like behaviour of top face sheet at a mid-span displacement of $34 \mathrm{~mm}$.

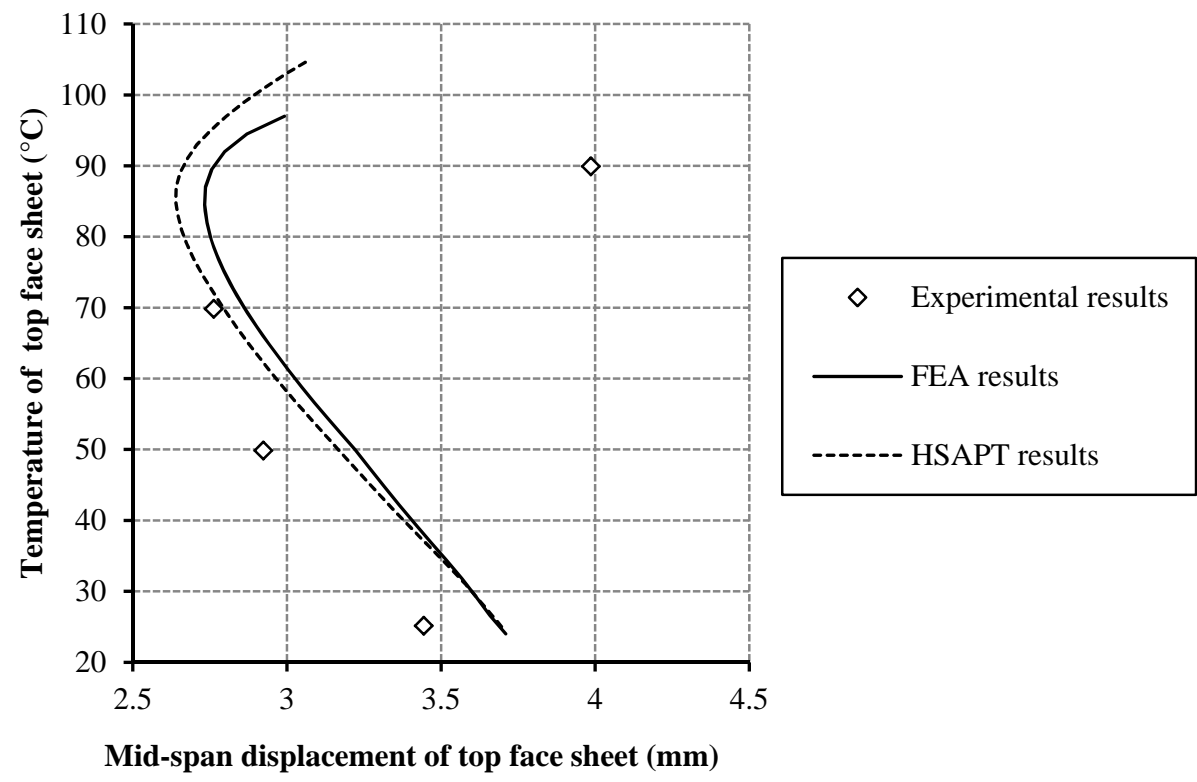

Figure 11: Equilibrium curves comparing HSAPT, elastic FE model predictions and experimental results. 
Palleti, H.N.K.T., Zhang, S., Dulieu-Barton, J.M., Fruehmann, R.K. and Thomsen, O.T., "Influence of thermomechanical interaction effects on the failure behaviour of polymer foam cored sandwich panels”, Journal of Sandwich Structures and Materials, 17, 2015, 308-331. DOI: 10.1177/1099636214567602.

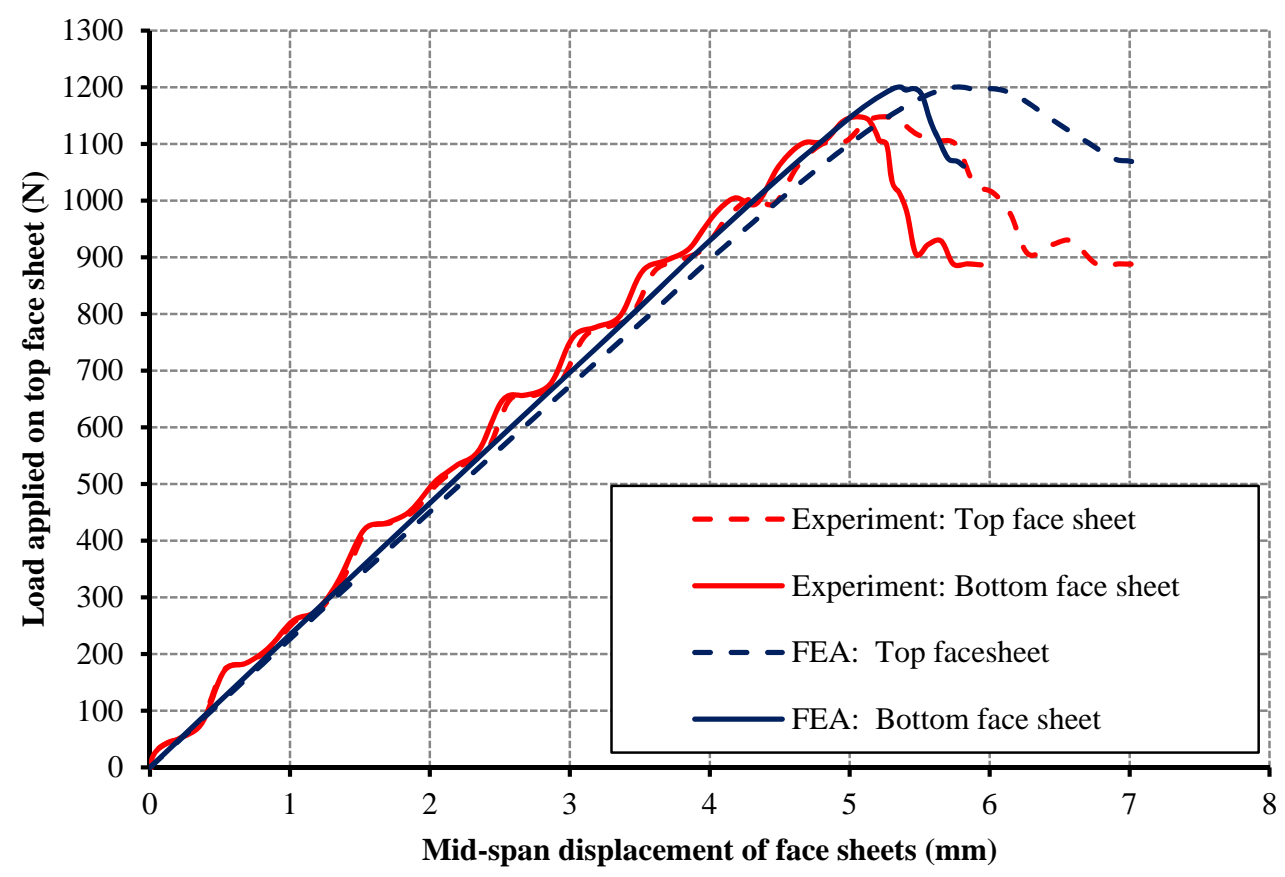

Figure 12: Comparison of experimental and nonlinear FE load-deflection curves at $25^{\circ} \mathrm{C}$.

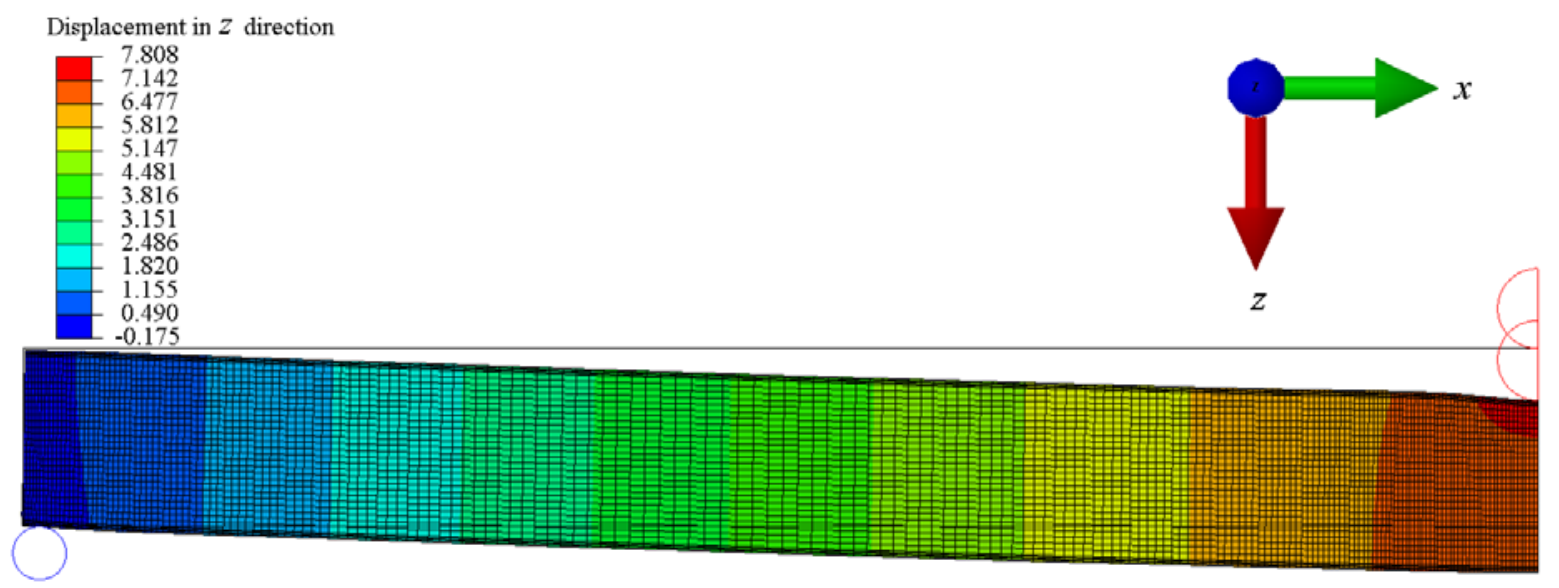

Figure 13: Vertical displacements predicted by elasto-plastic FE model at $25^{\circ} \mathrm{C}$ showing the mid-span indentation behaviour for a top face sheet mid-span displacement of $7.8 \mathrm{~mm}$. 
Palleti, H.N.K.T., Zhang, S., Dulieu-Barton, J.M., Fruehmann, R.K. and Thomsen, O.T., "Influence of thermomechanical interaction effects on the failure behaviour of polymer foam cored sandwich panels”, Journal of Sandwich Structures and Materials, 17, 2015, 308-331. DOI: 10.1177/1099636214567602.

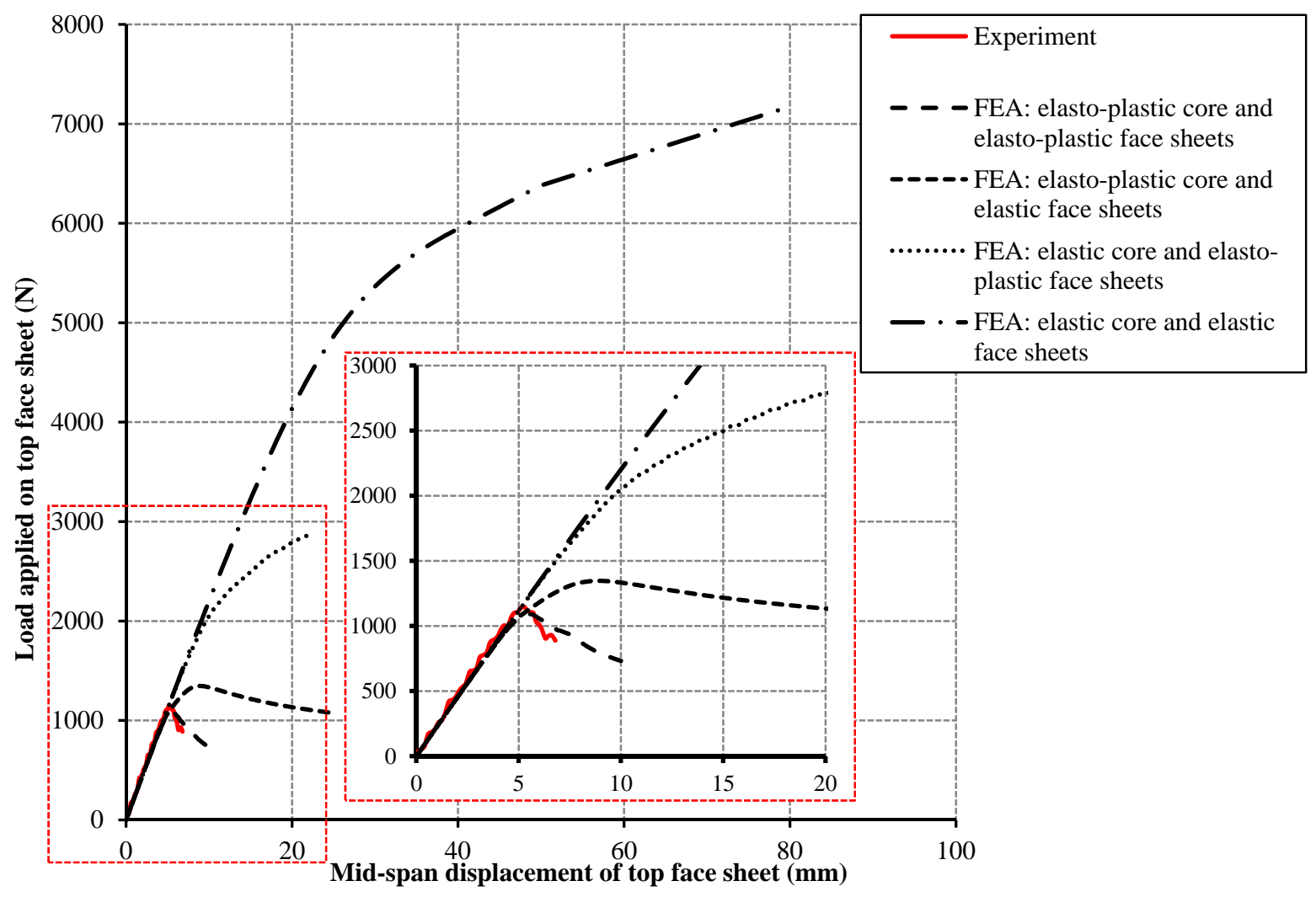

Figure 14: Comparison of nonlinear/elastic and nonlinear/elasto-plastic FE predictions with experimental observations. 